\title{
Parameters Symptomatic for Boron Toxicity in Leaves of Tomato Plants
}

\author{
Luis M. Cervilla, Begoña Blasco, Juan J. Rios, Miguel A. Rosales, Eva Sánchez-Rodríguez, \\ Maria M. Rubio-Wilhelmi, Luis Romero, and Juan M. Ruiz
}

Departament of Plant Physiology, Faculty of Sciences, University of Granada, 18071 Granada, Spain

Correspondence should be addressed to Juan M. Ruiz, jmrs@ugr.es

Received 23 January 2012; Accepted 22 February 2012

Academic Editor: Agustín González-Fontes

Copyright (C) 2012 Luis M. Cervilla et al. This is an open access article distributed under the Creative Commons Attribution License, which permits unrestricted use, distribution, and reproduction in any medium, provided the original work is properly cited.

\begin{abstract}
The incidence of boron (B) toxicity has risen in areas of intensive agriculture close to the Mediterranean sea. The objective of this research was to study the how $B$ toxicity $(0.5$ and $2 \mathrm{mM} \mathrm{B})$ affects the time course of different indicators of abiotic stress in leaves of two tomato genotypes having different sensitivity to B toxicity (cv. Kosaco and cv. Josefina). Under the treatments of $0.5 \mathrm{and} 2 \mathrm{mM}$ $\mathrm{B}$, the tomato plants showed a loss of biomass and foliar area. At the same time, in the leaves of both cultivars, the B concentration increased rapidly from the first day of the experiment. These results were more pronounced in the cv. Josefina, indicating greater sensitivity than in $\mathrm{cv}$. Kosaco with respect to excessive $\mathrm{B}$ in the environment. The levels of $\mathrm{O}_{2}{ }^{--}$and anthocyanins presented a higher correlation coefficient $(r>0.9)$ than did the levels of B in the leaf, followed by other indicators of stress, such as GPX, chlorophyll $\mathrm{b}$ and proline $(r>0.8)$. Our results indicate that these parameters could be used to evaluate the stress level as well as to develop models that could help prevent the damage inflicted by B toxicity in tomato plants.
\end{abstract}

\section{Introduction}

Boron (B) toxicity, an important agricultural problem that limits crop productivity in different regions of the world, can occur in B-rich soils or in soils exposed to B-rich irrigation waters, fertilizers, sewage sludge, or fly ash [1]. Boron toxicity can affect tomato (Solanum lycopersicum), which is one of the most widely grown vegetables worldwide, with more than 3 million ha under cultivation. Near the Mediterranean Sea, a large proportion of the tomato crop is grown under greenhouse plastic [2]. In the near future, B problems could intensify in Mediterranean areas due to the sparse rainfall and the ever-growing demand of desalinated water for agriculture in which the $\mathrm{B}$ concentration may be too high for healthy irrigation [3].

The typical symptoms shown by plants exposed to excess of B are reduced vigour, retarded development, leaf burn (chlorotic and necrotic patches in older leaves), and decreased number, size, and weight of fruits [1]. However, despite the importance of B toxicity for crop productivity, the mechanism by which plants respond to excess B is still not completely understood so that further investigation is needed. In this sense, one of the most common studies in plants submitted to abiotic stress is to determine the most reliable biochemical indicators of tolerance in order to use them as a selection criterion among different varieties or in developing resistant transgenic plants.

Notable among the biochemical indicators most widely used in plants subjected to different types of stress are those that define oxidative stress and different osmoprotective compounds $[4,5]$. Few studies are available on the antioxidant response of plants submitted to toxic levels of $\mathrm{B}$, and the results are inconclusive. In apple, Molassiotis et al. [6] and Sotiropoulos et al. [7], and in tomato plants, Cervilla et al. [8], observed that the nonenzymatic antioxidant activity (ascorbate and glutathione) intensified with a rise in the $\mathrm{B}$ concentration in the culture medium. Furthermore, these authors also found a significant increase in the $\mathrm{H}_{2} \mathrm{O}_{2}$ concentrations and lipid peroxidation. Nevertheless, previous studies have demonstrated that an excess of $\mathrm{B}$ 
could inhibit the formation of certain antioxidants, such as glutathione in the leaves of sunflower (Helianthus annuus; [9]) or tocopherol in orange (Citrus sinensis; [10]). On the other hand, one of the response mechanisms most thoroughly studied in stress situations is the accumulation of osmoprotective solutes, notably proline [11]. Among other activities, proline protects protein structure against denaturation, stabilizes cell membranes by interacting with phospholipids, acts as a detoxifier of hydroxyl radicals, and, furthermore, is an energy and $\mathrm{N}$ source in plants $[12,13]$. Some authors hold that proline can detoxify reactive oxygen species (ROS) by forming a complex with them and by inhibiting lipid peroxidation [14]. In this sense, Molassiotis et al. [6] suggested that a decline in the proline content in leaves could contribute to greater lipid peroxidation under conditions of excess B. However, data relating proline and B toxicity are still scant, so that the role of this molecule is still not clear regarding this nutritional stress.

Finally, another metabolic process that has been associated with the resistance responses to different types of abiotic stress in plants involves phenolic compounds. Phenols and their metabolism against this type of stress present two functions that help avoid the formation of ROS. Firstly, it has been confirmed that phenols can act as an absorption filter for radiation and can limit the excitation of chlorophyll under conditions unfavourable for the photosynthetic apparatus [15]. Secondly, phenolic compounds also show antioxidant action, which depends primarily on the number and position of hydroxyl groups in their structure. In agreement with Harborne and Williams [15], the antioxidant action mechanism may include (a) suppression of the formation of reactive species by the enzyme inhibition; (b) sequestering of ROS; (c) overregulation or protection of antioxidant systems. The effect of B toxicity over this metabolic process has also received meagre attention, the most relevant work perhaps being that of Keles et al. [10]. These authors, working in citrus irrigated with water containing high B concentrations, noted significant changes in the foliar phenol concentration.

In short, given the growing importance of B toxicity in agriculture, mainly in zones of intensive horticulture and where fertigation involves brackish or desalinated water, the present work evaluates two varieties of cherry tomato having different degrees of sensitivity to B toxicity $[8,16,17]$, examining the temporal reaction to different abiotic-stress indicators in the leaves in order to select the parameters that are most indicative of the toxic B levels in the plant.

\section{Materials and Methods}

2.1. Plant Material and Growth Conditions. The two cultivars of tomato plants (Solanum lycopersicum L. (Lycopersicon esculentum Mill.)) used in the present study were Josefina and Kosaco. Seeds of the two cultivars were germinated and grown for 30 days in cell flats (cell size, $3 \mathrm{~cm} \times 3 \mathrm{~cm} \times 10 \mathrm{~cm}$ ) filled with a peatlite mixture, and the flats were placed on benches in an experimental greenhouse in southern Spain (Granada, Saliplant S.L.). The 30-day-old seedlings were transferred to a controlled environmental chamber used with relative humidity of $60-80 \%$, temperature $25^{\circ} \mathrm{C} / 15^{\circ} \mathrm{C}$ (day/night), and $16 \mathrm{~h} / 8 \mathrm{~h}$ photoperiod at a PPFD (photosynthetic photon-flux density) of $350 \mu \mathrm{mol} \mathrm{m}^{-2} \mathrm{~s}^{-1}$ (measured at the top of the plants with a $190 \mathrm{SB}$ quantum sensor, LI-COR Inc., Lincoln, NE, USA). Plants were grown in individual pots $(25 \mathrm{~cm}$ upper diameter, $17 \mathrm{~cm}$ lower diameter, $25 \mathrm{~cm}$ in height) of $8 \mathrm{~L}$ volume, filled with vermiculite. Throughout the experiment, the plants were grown in a nutrient solution containing: $4 \mathrm{mM} \mathrm{KNO} 3,3 \mathrm{mM} \mathrm{Ca}\left(\mathrm{NO}_{3}\right)_{2}, 2 \mathrm{mM}$ $\mathrm{MgSO}_{4}, 1 \mathrm{mM} \mathrm{KH}_{2} \mathrm{PO}_{4}, 1 \mathrm{mM} \mathrm{NaH} \mathrm{PO}_{4}, 2 \mu \mathrm{M} \mathrm{MnCl}_{2}$, $1 \mu \mathrm{M} \mathrm{ZnSO}_{4}, 0.25 \mu \mathrm{M} \mathrm{CuSO}_{4}, 0.1 \mu \mathrm{M} \mathrm{Na}_{2} \mathrm{MoO}_{4}, 5 \mu \mathrm{M}$ FeEDDHA and $50 \mu \mathrm{M} \mathrm{H}_{3} \mathrm{BO}_{3}$. The nutrient solution $(\mathrm{pH}$ 5.8) was renewed every 3 days and the vermiculite partly rinsed with Millipore-filtered water in order to avoid nutrient accumulation.

The B treatments $\left(0.50 \mathrm{mM}\right.$ and $\left.2.00 \mathrm{mM} \mathrm{H}_{3} \mathrm{BO}_{3}\right)$ were started 42 days after sowing and maintained for 15 days, when most of the Josefina plants showed clear symptoms of B toxicity. The control treatment received the complete nutrient solution alone $(0.05 \mathrm{mM} \mathrm{B})$. The experimental design was a randomized complete block with three treatments, arranged in individual pots with six plants per treatment, and three replicates. The experiment was repeated three times under the same conditions $(n=9)$.

2.2. Plant Sampling. Leaves were sampled at $0,5,10$, and 15 days after the beginning of the B treatments. Two plants per treatment and sampling were taken from each replicate. The leaves were rinsed three times in distilled water after disinfection with $1 \%$ nonionic detergent and then blotted with filter paper. The leaves from half of the plants in each treatment were used fresh for the analysis of the concentrations of $\mathrm{O}_{2}{ }^{--}, \mathrm{H}_{2} \mathrm{O}_{2}, \mathrm{MDA}$, proline, chlorophyll a and b, carotenoids, anthocyanins, total phenolic compounds, flavonoids, and the enzymatic activities of GPX and polyphenol oxidase (PPO). The rest of the leaves were lyophilized and used to determine the biomass and $\mathrm{B}$ concentration.

2.3. Foliar Area. To analyse the foliar area, all the leaves of each plant with a size larger than $2 \mathrm{~cm}$ in length were digitalized by a scanner (CanoScan 5000F, Canon). Afterwards, the original digital image was processed with Adobe Photoshop v.9.0 to provide and black-and-white image. From this image, the foliar area was calculated $\left(\mathrm{cm}^{2}\right.$ per plant) using the program ImageJ v.1.41 (National Institute of Health, EEUU).

2.4. Boron Analysis. The total B concentration was analysed after digestion of $0.15 \mathrm{~g}$ dry and milled leaf material with $\mathrm{H}_{2} \mathrm{SO}_{4}(5 \mathrm{~mL}$ at $98 \%)$ and $\mathrm{H}_{2} \mathrm{O}_{2}(30 \%)$. To measure B concentration, the azomethine- $\mathrm{H}$ method was followed and the absorbance was read by spectrophotometry at $410 \mathrm{~nm}$ [18].

2.5. Concentration of $\mathrm{O}_{2}{ }^{\bullet-}, \mathrm{H}_{2} \mathrm{O}_{2}$ and, $\mathrm{MDA}$. The detection of $\mathrm{O}_{2}{ }^{--}$was based on its ability to reduce nitro blue tetrazolium (NBT) [19] and measured as described by Kubis [20]. A batch of $0.1 \mathrm{~g}$ of fresh leaves were cut into $1 \mathrm{~mm}$ fragments and immersed in $10 \mathrm{mM}$ K-phosphate buffer, $\mathrm{pH} 7.8$, containing $0.05 \%(\mathrm{w} / \mathrm{v}) \mathrm{NBT}$, and $10 \mathrm{mM}$ sodium azide $\left(\mathrm{NaN}_{3}\right)$, and left for $1 \mathrm{~h}$ at room temperature. After 

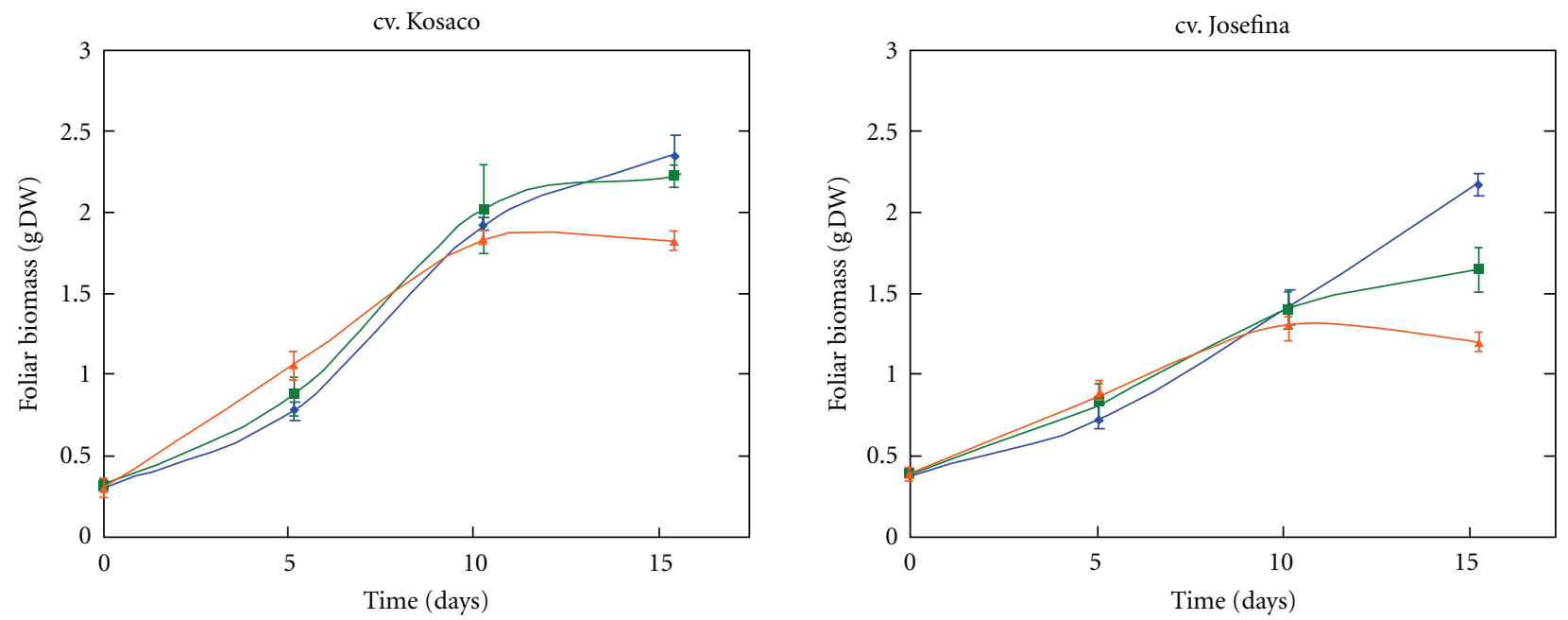

(a)
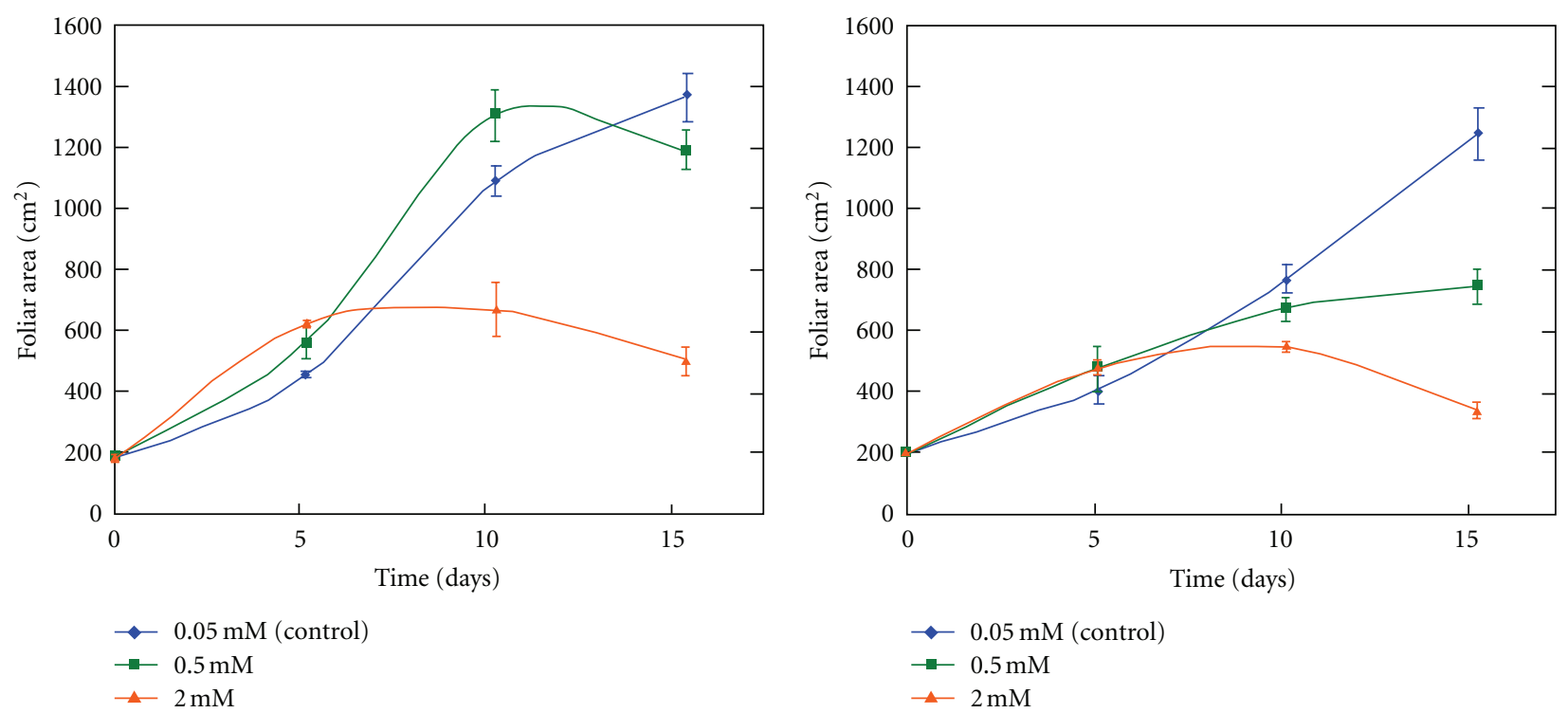

(b)

Figure 1: Changes in foliar biomass (a) and foliar area (b) over 15 days in two tomato cultivars (Kosaco and Josefina) subjected to $0.05,0.5$, and $2 \mathrm{mM}$ of $\mathrm{B}$. The data represented are means $(n=9) \pm \mathrm{SE}$.

incubation, $2 \mathrm{~mL}$ of the reaction solution was heated at $85^{\circ} \mathrm{C}$ for $15 \mathrm{~min}$ and cooled rapidly. Optical density was measured at a wavelength of $580 \mathrm{~nm}$.

The $\mathrm{H}_{2} \mathrm{O}_{2}$ content of leaf samples was colorimetrically measured as described by Mukherjee and Choudhuri [21]. Leaf samples were extracted with cold acetone to determine the $\mathrm{H}_{2} \mathrm{O}_{2}$ levels. An aliquot $(1 \mathrm{~mL})$ of the extracted solution was mixed with $200 \mu \mathrm{L}$ of $0.1 \%$ titanium dioxide in $20 \%$ $(\mathrm{v}: \mathrm{v}) \mathrm{H}_{2} \mathrm{SO}_{4}$ and the mixture was then centrifuged at $6000 \times \mathrm{g}$ for $15 \mathrm{~min}$. The intensity of yellow colour of the supernatant was measured at $415 \mathrm{~nm}$. The $\mathrm{H}_{2} \mathrm{O}_{2}$ concentration was calculated from a standard curve plotted within the range of $100-1000 \mathrm{nmol} \mathrm{H}_{2} \mathrm{O}_{2}$.

For the MDA assay, leaves were homogenized with $5 \mathrm{~mL}$ of $50 \mathrm{mM}$ solution containing $0.07 \%$ of $\mathrm{NaH}_{2} \mathrm{PO}_{4} \cdot 2 \mathrm{H}_{2} \mathrm{O}$ and $1.6 \% \mathrm{Na}_{2} \mathrm{HPO}_{4} \cdot 12 \mathrm{H}_{2} \mathrm{O}$, ground with a mortar and pestle, and centrifuged at $20,000 \mathrm{xg}$ for $25 \mathrm{~min}$ in a refrigerated centrifuge. For measurement of MDA concentration, $4 \mathrm{~mL}$ of $20 \%$ trichloroacetic acid containing $0.5 \%$ thiobarbituric acid was added to a $1 \mathrm{~mL}$ aliquot of the supernatant. The mixture was heated at $95^{\circ} \mathrm{C}$ for $30 \mathrm{~min}$ and then quickly cooled in an ice bath. After the tube was centrifuged at $10,000 \times \mathrm{g}$ for $10 \mathrm{~min}$, the absorbance of the supernatant was read at $532 \mathrm{~nm}$. The value for the nonspecific absorption at $600 \mathrm{~nm}$ was subtracted from the $532 \mathrm{~nm}$ reading. The concentration of MDA was calculated using the MDA extinction coefficient of $155 \mathrm{mM}^{-1} \mathrm{~cm}^{-1}$ [22].

2.6. Proline Concentration. For the determination of the freeproline concentration, leaves were homogenized in $5 \mathrm{~mL}$ of ethanol at $96 \%$. The insoluble fraction of the extract was washed with $5 \mathrm{~mL}$ of ethanol at $70 \%$. The extract was 
cv. Kosaco

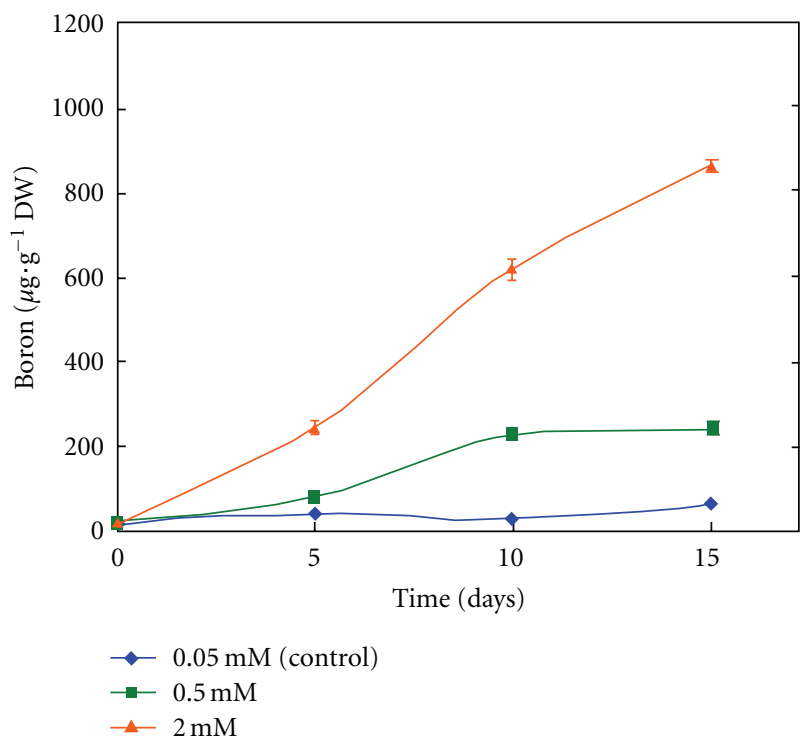

cv. Josefina

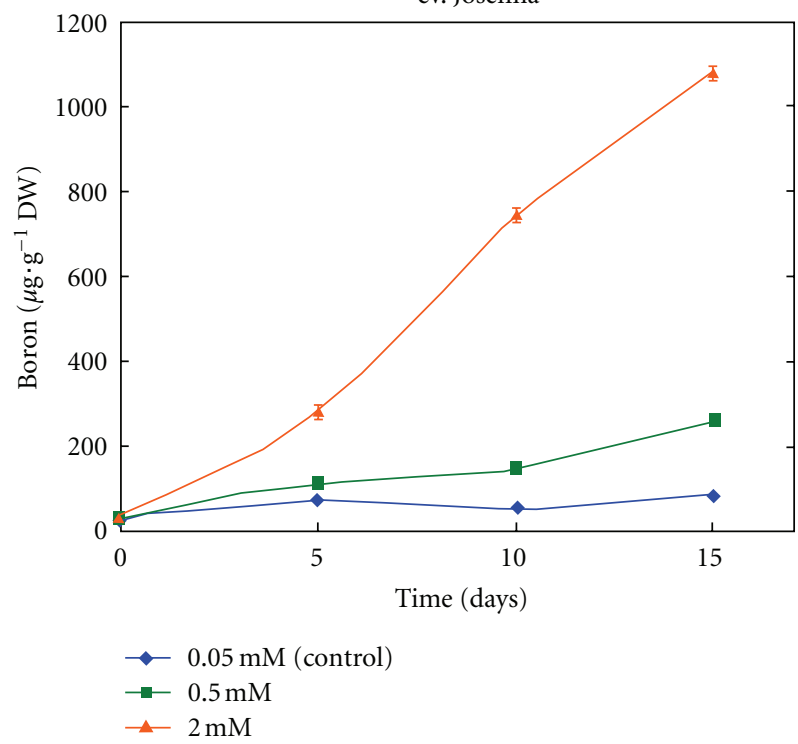

Figure 2: Changes in the foliar B concentration over 15 days in two tomato cultivars (Kosaco and Josefina) subjected to $0.05,0.5$, and 2 mM of B. The data represented are means $(n=9) \pm \mathrm{SE}$.

centrifuged at $3500 \mathrm{~g}$ for $10 \mathrm{~min}$ and the supernatant was preserved $4^{\circ} \mathrm{C}$ for the proline determination following Irigoyen et al. [23]. An aliquot of this supernatant was taken and, after adding reactive ninhydrin acid reagent (ninhydrin, phosphoric acid $6 \mathrm{M}$, glacial acetic acid $60 \%$ ) and glacial acetic acid at $99 \%$, was placed in a bath at $100^{\circ} \mathrm{C}$. After $45 \mathrm{~min}$, the tubes were cooled and $5 \mathrm{~mL}$ of benzene were added, and the absorbance of the organic phase was measured.

2.7. Chlorophyll and Carotenoid Concentrations. For the extraction of chlorophylls and carotenoids, $0.15 \mathrm{~g}$ of leaves were ground in semidarkness and resuspended in $10 \mathrm{~mL}$ of cold acetone at $80 \%$. Immediately afterwards, the samples were centrifuged at $3000 \times \mathrm{g}$ and the absorbance of the supernatant was measured at 663,646 , and $470 \mathrm{~nm}$. The concentrations of chlorophyll $\mathrm{a}$ and $\mathrm{b}$ as well as carotenoid were calculated following Wellburn [24].

2.8. Determination of Anthocyanins, Total Phenolic, and Flavonoid Compounds. Anthocyanins were analysed following the procedure of Ticconi et al. [25]. For this, $2 \mathrm{~g}$ FW were homogenized in a solution containing propanol, chlorhydric acid, and water (18:1:81). Afterwards, the homogenates were boiled in a water bath for $3 \mathrm{~min}$ and left in darkness $24 \mathrm{~h}$. Afterwards, $3 \mathrm{~mL}$ of the supernatant were centrifuged at $6500 \mathrm{rpm}$ for $40 \mathrm{~min}$. Finally, the samples were measured at $A_{535}$ and $A_{650} \mathrm{~nm}$ and the data were expressed as optical density (OD). The absorbance value was calculated and corrected by the formula:

$$
A=A_{535}-A_{650} .
$$

The phenols of the plant material were extracted with $\mathrm{MeOH}$. Total phenolic content was assayed quantitatively by absorbance at $765 \mathrm{~nm}$ with Folin-Ciocalteau reagent [26]. The total flavonoids content was measured by a colorimetric method [27] with minor modifications. The extraction solution used was the same as phenolic compounds. Aliquots $(0.5 \mathrm{~mL})$ of diluted or standard solutions were pipetted into $15 \mathrm{~mL}$ polypropylene conical tubes containing $2 \mathrm{~mL}$ of double-distilled $\mathrm{H}_{2} \mathrm{O}$ and mixed with $0.15 \mathrm{~mL}$ of $5 \%$ $\mathrm{NaNO}_{2}$. After $5 \mathrm{~min}, 0.15 \mathrm{~mL}$ of $10 \% \mathrm{AlCl}_{3} \cdot 6 \mathrm{H}_{2} \mathrm{O}$ solution was added; the mixture was allowed to stand for another $5 \mathrm{~min}$, and then $1 \mathrm{~mL}$ of the $1 \mathrm{M} \mathrm{NaOH}$ was added. The reaction solution was mixed well and kept for $15 \mathrm{~min}$, and the absorbance was determined at $A_{415}$.

2.9. $P P O$ and GPX Activities. For determination of $P P O$ (EC 1.10.3.2) activity, leaves were homogenized in $50 \mathrm{mM}$ potassium phosphate buffer $(\mathrm{pH} 7.0)$. Homogenates were centrifuged at $15,000 \mathrm{~g}$ for $15 \mathrm{~min}$ at $4^{\circ} \mathrm{C}$. PPO assay was performed in mixture containing $2.85 \mathrm{~mL}$ of $50 \mathrm{mM}$ potassium phosphate buffer ( $\mathrm{pH} 7.0$ ), $50 \mu \mathrm{L}$ of $60 \mathrm{mM}$ catechol, and $0.1 \mathrm{~mL}$ of supernatant. Increase in absorbance was

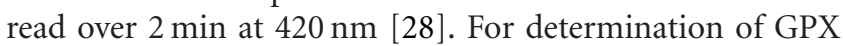
(EC 1.11.1.7) the extract buffer was $50 \mathrm{mM}$ tris- $\mathrm{HCl}(\mathrm{pH}$ 7.5) containing $5 \mathrm{mM}$ mercaptoethanol, $2 \mathrm{mM}$ dithiothreitol (DTT), $0.5 \mathrm{mM}$ PMSF and $2 \mathrm{mM}$ EDTA-Na. Homogenates were centrifuged at $16,500 \mathrm{~g}$ for $30 \mathrm{~min}$ at $4^{\circ} \mathrm{C}$. GPX activity was determined by following the method by Kalir et al. [29].

2.10. Statistical Analysis. The data were submitted to a one-way analysis of variance (ANOVA) and the differences between the means were compared by the Fisher's leastsignificant difference test (LSD; $P=0.05$ ), using the program Statgraphics 6.1. On the other hand, to study the effect of the cultivar, treatment, and sampling day separately, a factorial ANOVA was used in which the $F$ statistic was noted 

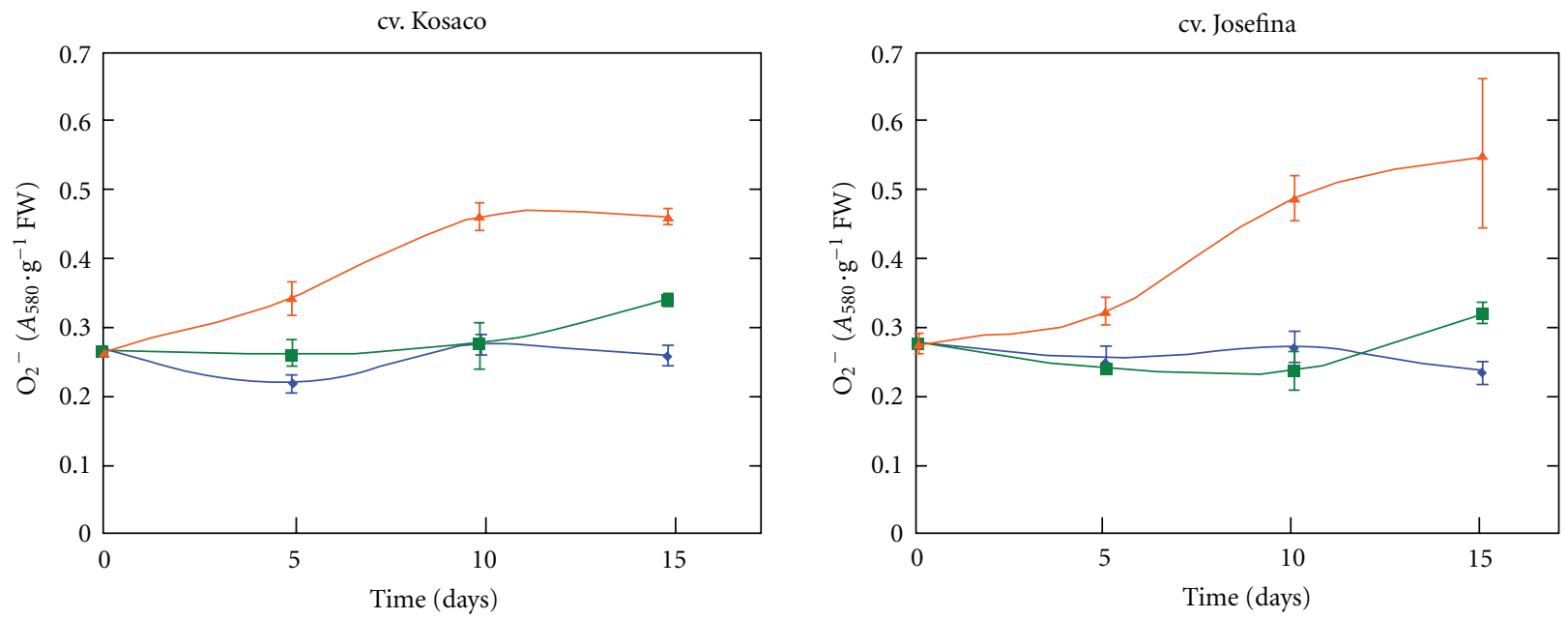

(a)
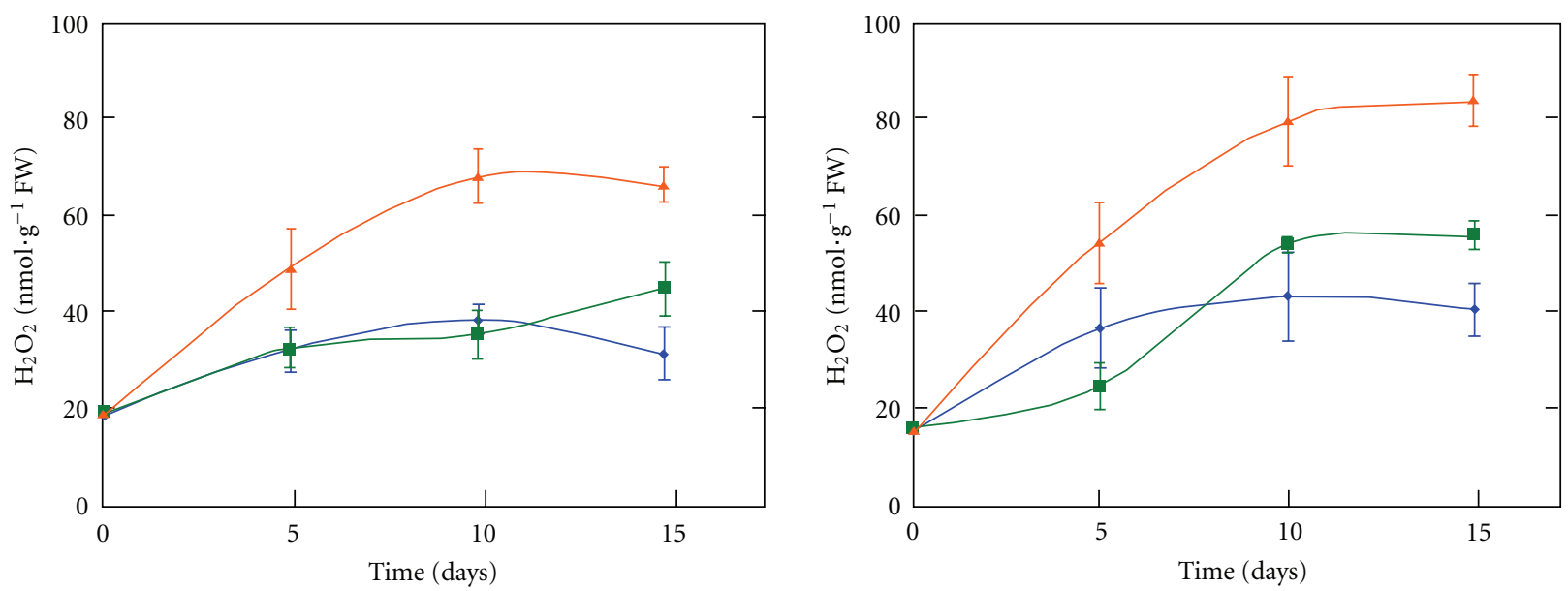

(b)
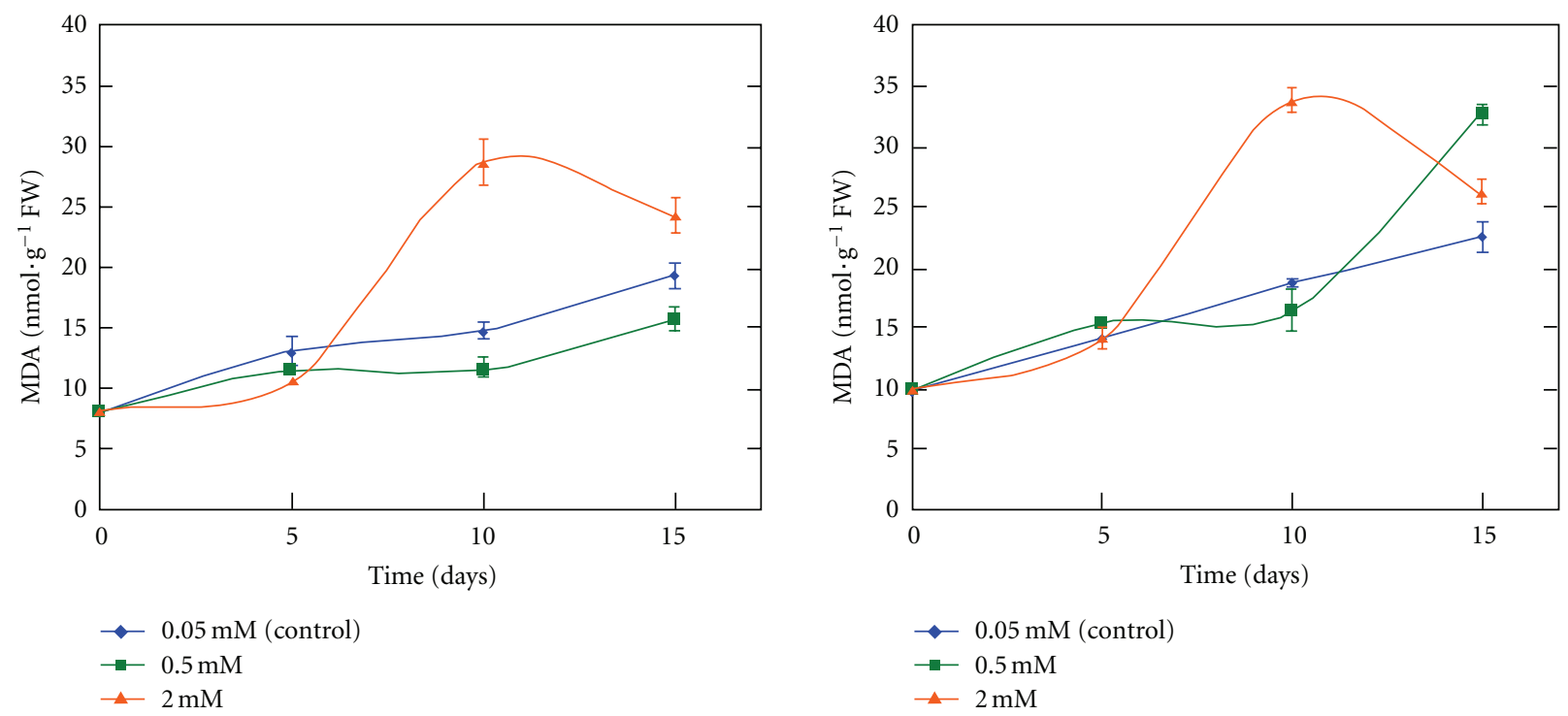

(c)

FIGURE 3: Changes in the foliar concentration of $\mathrm{O}_{2}{ }^{-}$(a), $\mathrm{H}_{2} \mathrm{O}_{2}$ (b), and MDA (c) over 15 days in two tomato cultivars (Kosaco and Josefina) subjected to $0.05,0.5$, and $2 \mathrm{mM}$ of $\mathrm{B}$. The data represented are means $(n=9) \pm \mathrm{SE}$. 

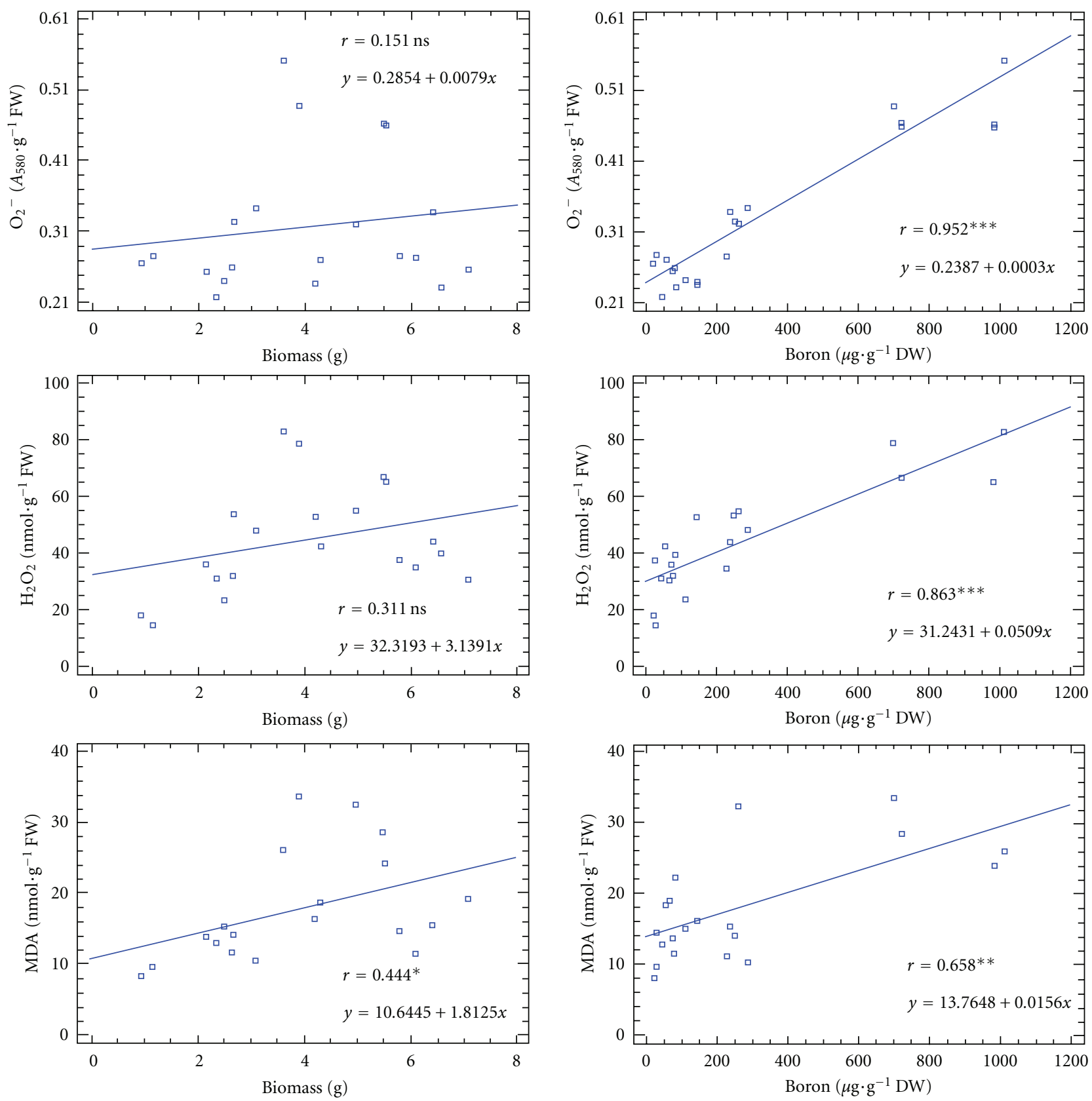

Figure 4: Analysis of the lineal regression where biomass ( $x$ axis, left) and the foliar concentration in $\mathrm{B}$ ( $x$ axis, right) are compared with the concentration of $\mathrm{O}_{2}{ }^{-}, \mathrm{H}_{2} \mathrm{O}_{2}$, and MDA ( $y$ axis) in the leaves of two tomato cultivars (Kosaco and Josefina). The significance levels are represented by $*(P<0.05),{ }^{* *}(P<0.01),{ }^{* * *}(P<0.001)$ and ns (non-significant; $\left.P>0.05\right)$.

and represented in each case. The significance levels were represented as: $*(P<0.05), * *(P<0.01), * * *(P<0.001)$ and ns (not significant, $P>0.05$ ).

\section{Results and Discussion}

3.1. Growth and B Accumulation. Only on day 15 after the beginning of the treatments was a significant reduction in foliar biomass detected after the B-toxicity treatments (Figure 1(a)). However, on day 10, both cultivars showed a loss in leaf area under the 2-mM treatment (Figure 1(b)).
The lack of compensation over time between biomass and leaf area was probably due to the amount of necrosis in the leaves subjected to toxic B levels, this appearing before day 10. In the case of $\mathrm{cv}$. Josefina, a sharp reduction was also noted in the biomass and leaf area with respect to the control treatment of $0.5 \mathrm{mM}$ de B (Figure 1), suggesting, as reported in several other works $[8,16,17]$, that this cultivar has greater B-toxicity sensitivity than does cv. Kosaco.

The foliar concentration of B rapidly increased with the toxicity treatments, an effect that was evident from day 5 in plants grown under the $2 \mathrm{mM}$ treatment (Figure 2). In 

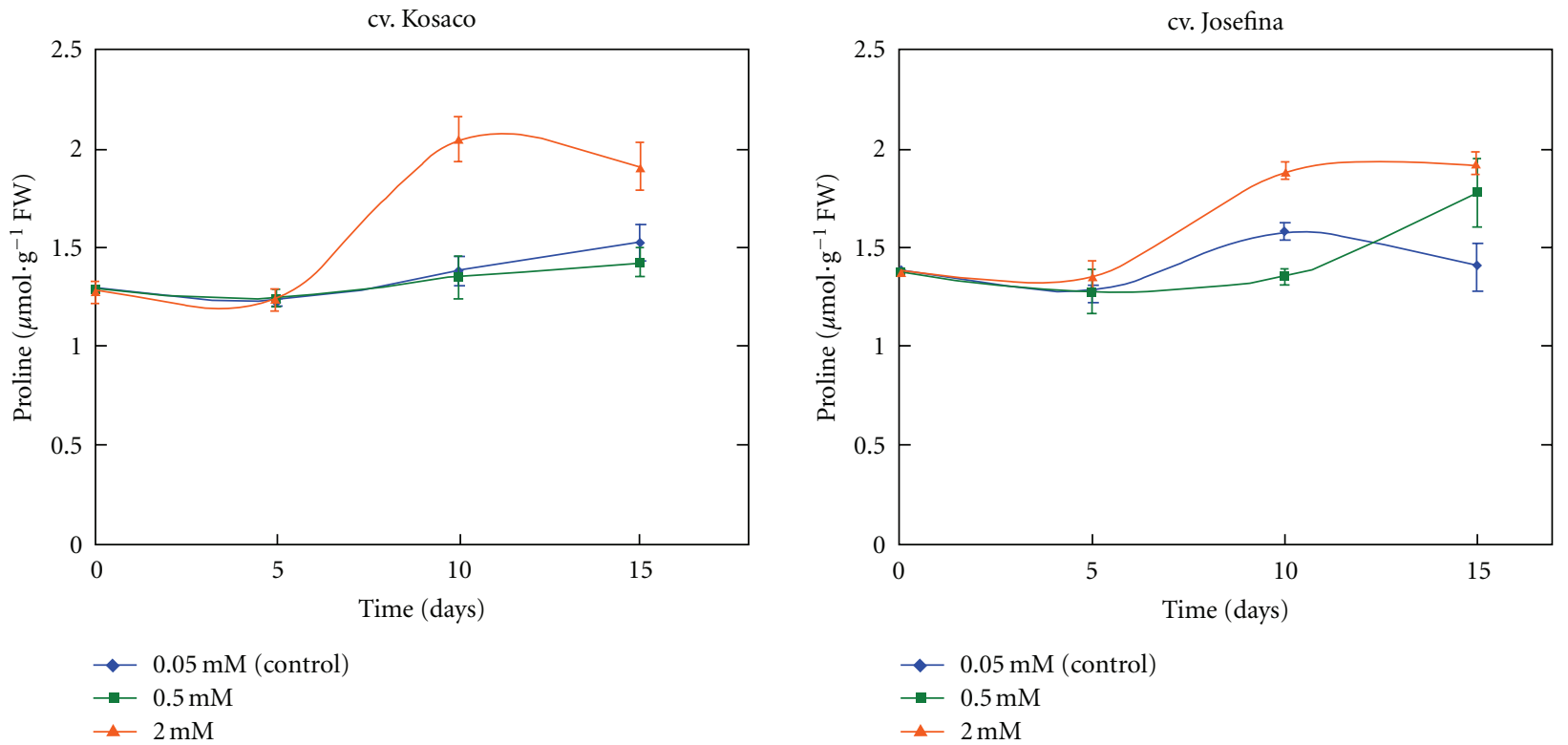

Figure 5: Changes in the foliar concentration of proline over 15 days in two tomato cultivars (Kosaco and Josefina) subjected to 0.05 , 0.5 , and $2 \mathrm{mM}$ of $\mathrm{B}$. The data represented are means $(n=9) \pm \mathrm{SE}$.
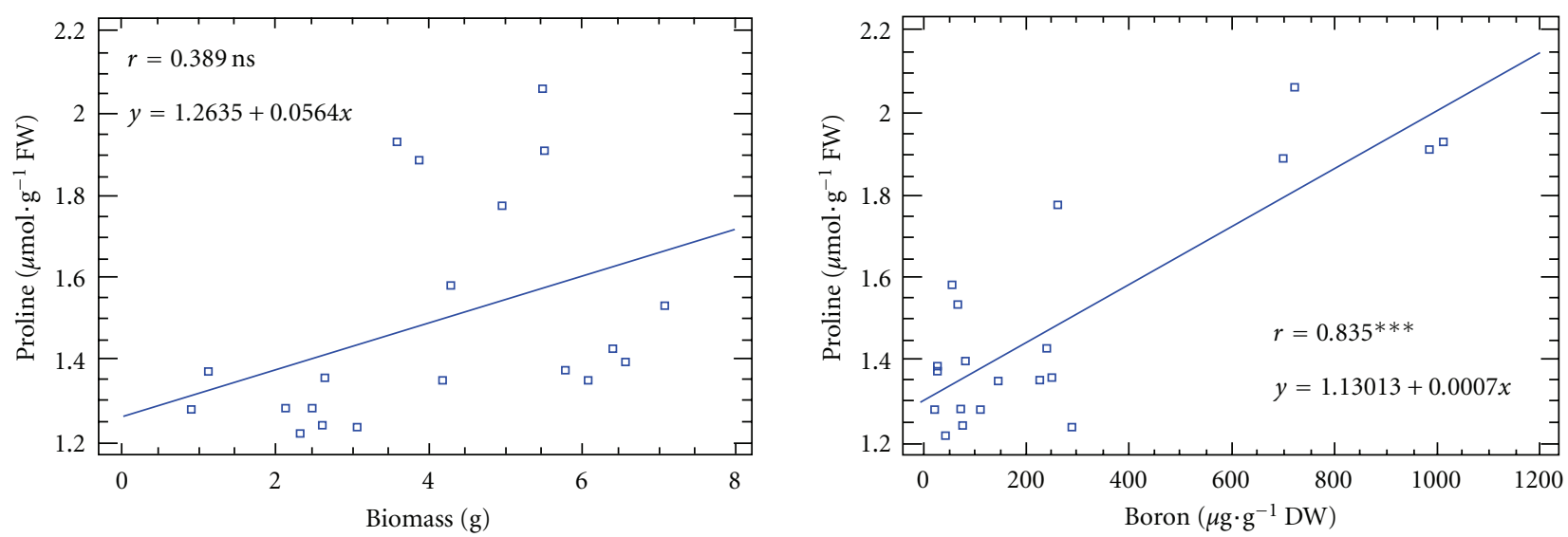

Figure 6: Analysis of the lineal regression where biomass ( $x$-axis, left) and the foliar concentration in B ( $x$-axis, right) are compared with the concentration of proline ( $y$-axis) in the leaves of two tomato cultivars (Kosaco and Josefina). The significance levels are represented by $*(P<0.05),{ }^{* *}(P<0.01),{ }^{* *}(P<0.001)$, and ns (nonsignificant; $\left.P>0.05\right)$.

addition to the treatments, the type of cultivar also had a significant effect on the levels of B in the leaf (Table 1). In this sense, on days 10 and 15, cv. Josefina registered the highest foliar concentration of this element (Figure 2). On the other hand, our results show that the tomato plants submitted to excessive $\mathrm{B}$ were capable of maintaining their growth for a certain period despite an accumulation of B in the leaves far higher than the plants grown under control conditions. This phenomenon was more evident in the cv. Kosaco, in which the plants administered $0.5 \mathrm{mM}$ of B showed growth very similar to that of control (Figure 1(a)), despite having twice the foliar concentration in B (Figure 2).

Whereas many plants that are tolerant to trace elements (metals and metalloids) exclude or limit the uptake of these elements, as occurs in certain genotypes of barley tolerant to B toxicity [1], other plants are capable of accumulating such elements while maintaining growth, the latter being defined in many cases as hyperaccumulators [30]. In this sense, it has recently been found that some species can grow in soils with toxic B levels in spite of showing high foliar concentrations of this element [31]. Although the tomato cultivars used in the present experiment do not appear to be hyperaccumulators, our data indicate that, while not having any exclusion mechanism for $\mathrm{B}$, they are capable of maintaining a relatively high growth index despite accumulating $\mathrm{B}$ concentrations much higher than registered under optimal conditions $(0.05 \mathrm{mM})$, this capability being particularly evident in cv. Kosaco $[8,16]$. 

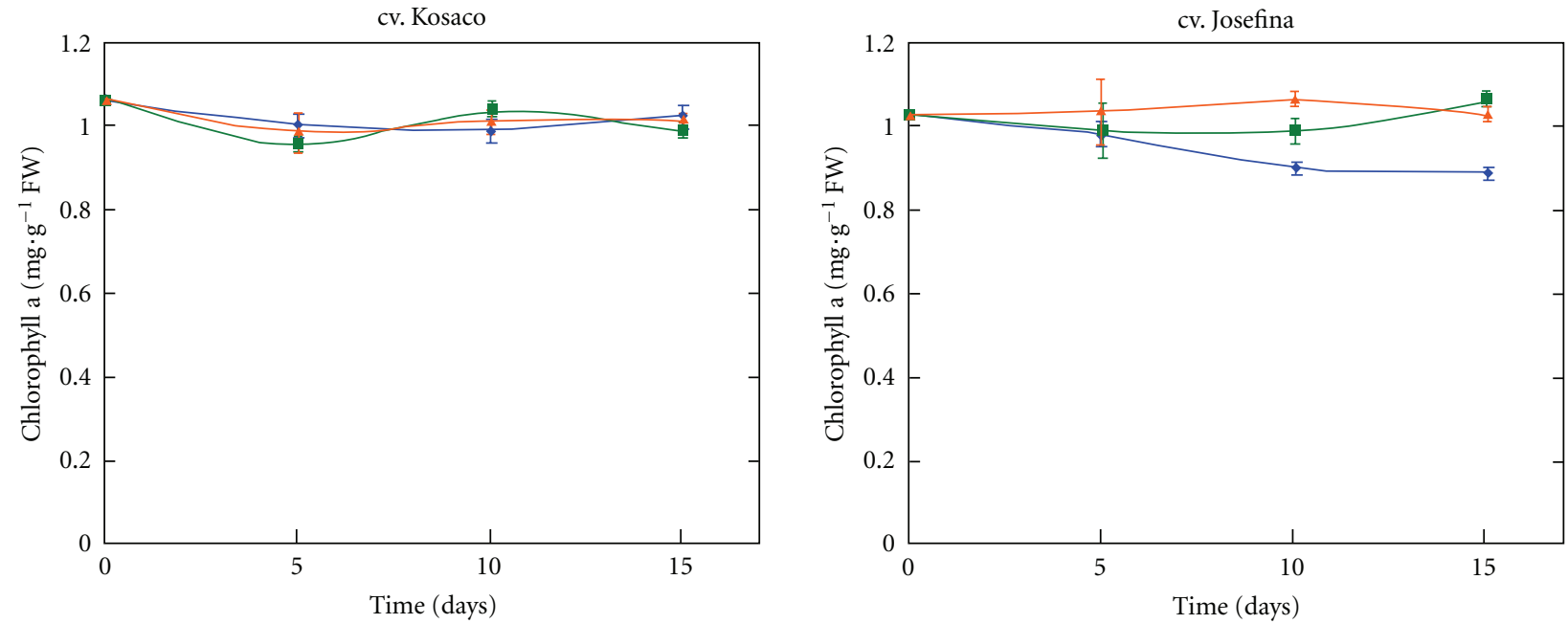

(a)
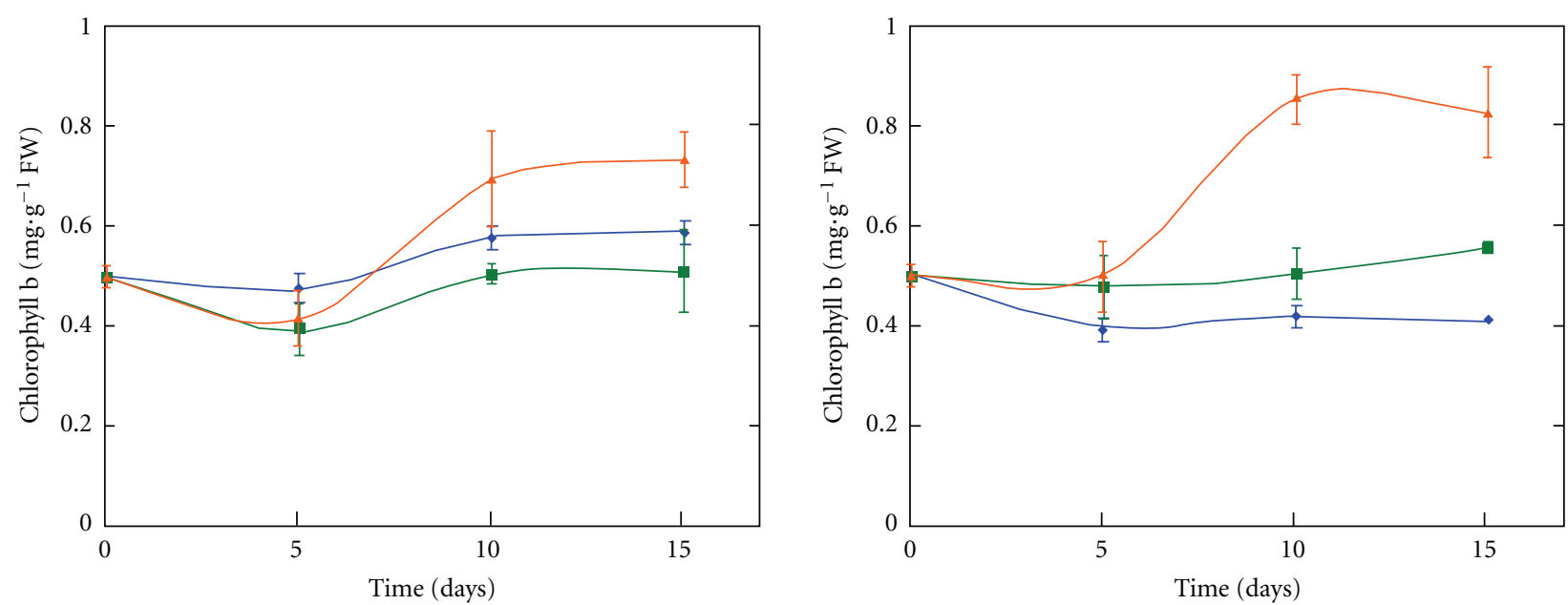

(b)
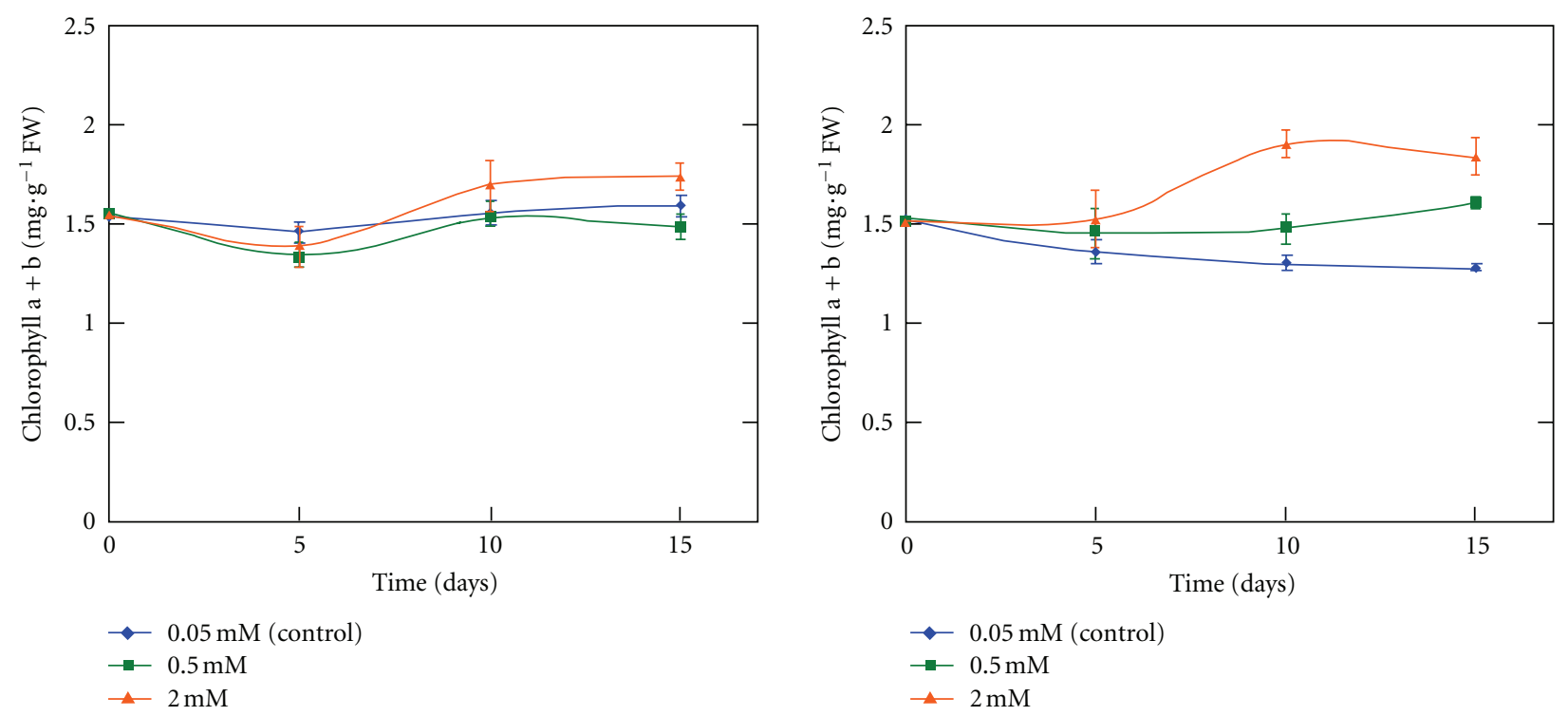

(c)

FIgURE 7: Changes in the foliar concentration of chlorophyll a (a), chlorophyll b (b), and chlorophyll a + b (c) over 15 days in two tomato cultivars (Kosaco and Josefina) subjected to $0.05,0.5$, and $2 \mathrm{mM}$ of B. The data represented are means $(n=9) \pm \mathrm{SE}$. 

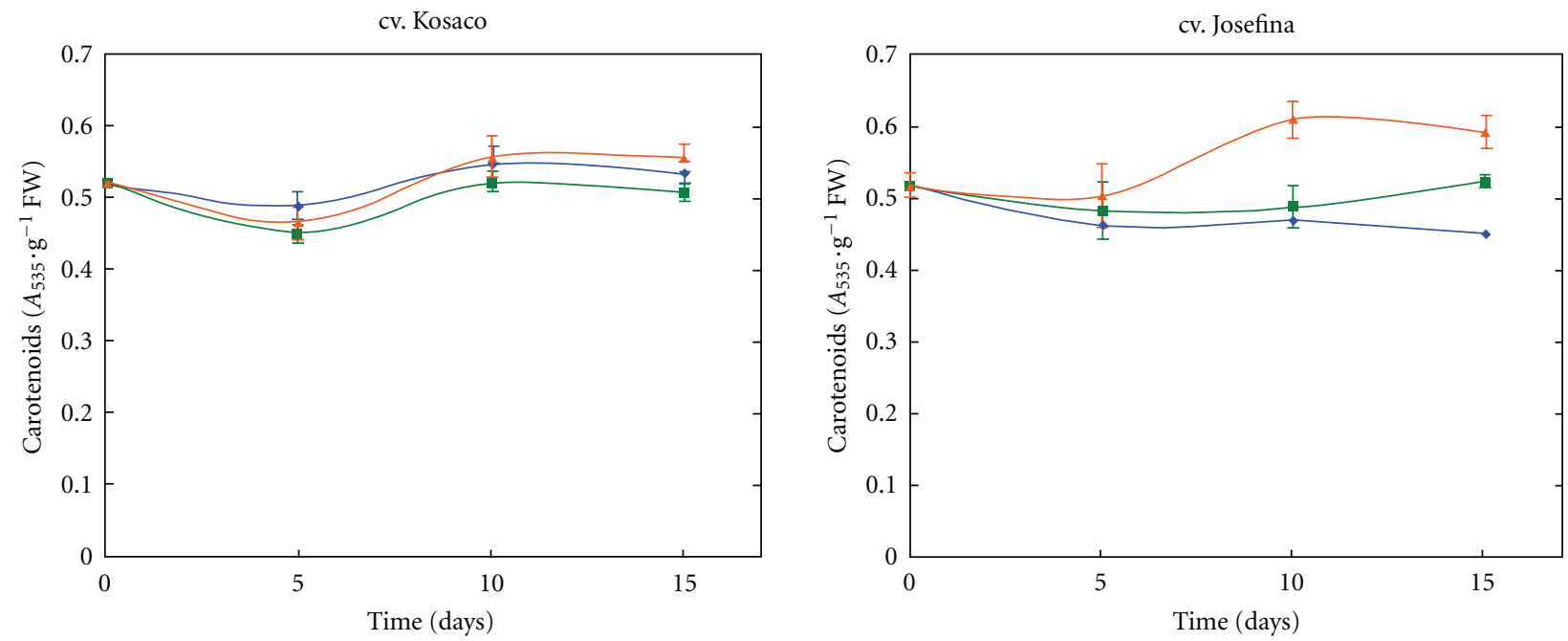

(a)
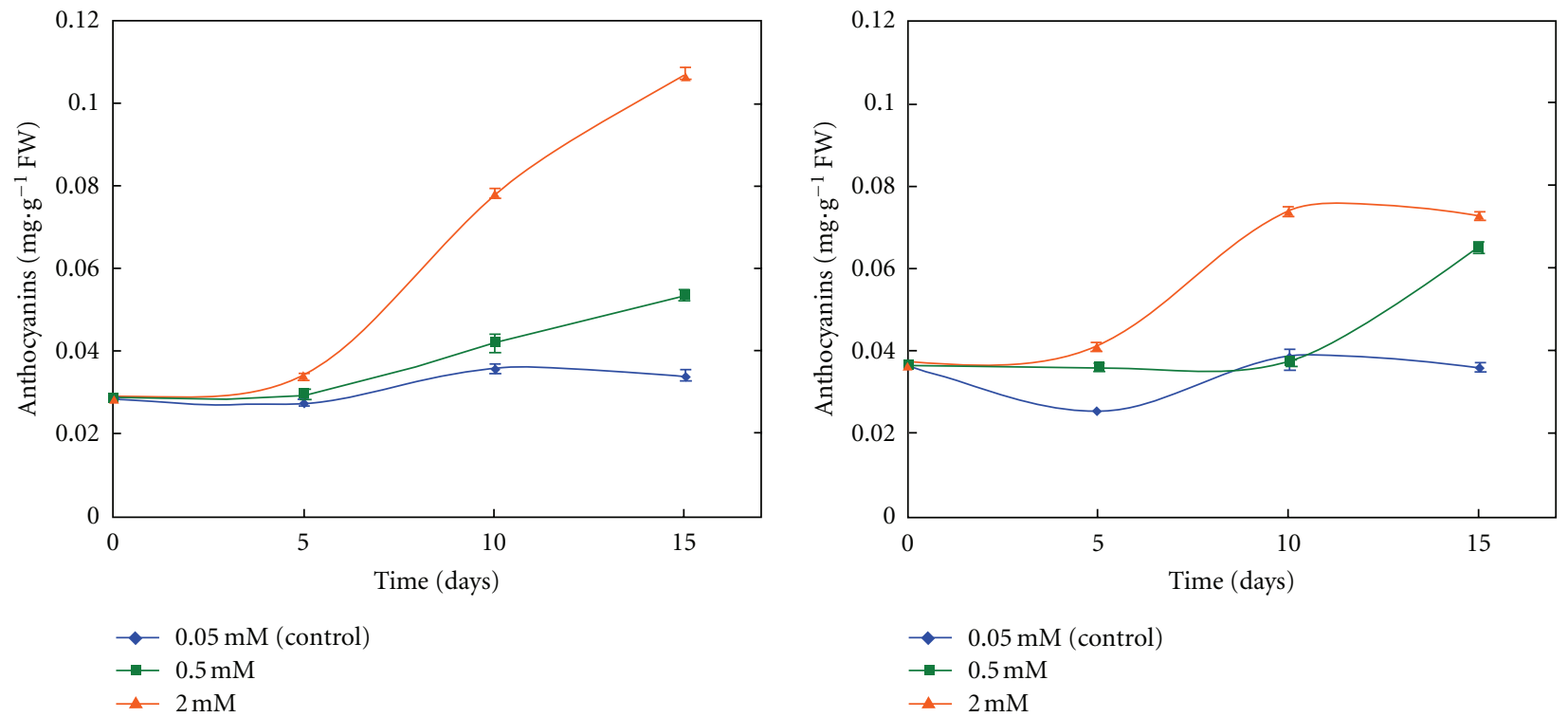

(b)

FIGURE 8: Changes in the foliar concentration of carotenoids (a), and anthocyanins (b) over 15 days in two tomato cultivars (Kosaco and Josefina) subjected to $0.05,0.5$, and $2 \mathrm{mM}$ of $\mathrm{B}$. The data represented are means $(n=9) \pm \mathrm{SE}$.

3.2. Stress Indicators. Different types of abiotic stress can have similar effects on the plant, although each separately promotes certain conditions to which the plant responds in a specific way [32]. Therefore, the study of each adverse situation requires greater knowledge of the parameters that best identify the presence of a given type of stress in the plant. Notable among the diverse parameters that are generally analysed with regard to different types of abiotic stress are oxidative damage, osmoregulation, light reception, and phenolic metabolism $[4,5]$.

Boron toxicity can promote the appearance of ROS, which can damage metabolic processes, altering membranes through lipid peroxidation, and provoking cell death in the plant [32]. In the present experiment, an analysis concerning the temporal trend of $\mathrm{O}_{2}{ }^{--}$and $\mathrm{H}_{2} \mathrm{O}_{2}$ accumulation in the leaf revealed a similar pattern in both tomato cultivars, reflecting an increase from day 5 in the treatment with $2 \mathrm{mM}$ of B (Figures 3(a) and 3(b)). In relation to the MDA concentration, increases with respect to control were found only on days 10 and 15 , with a notable accumulation peak on day 10 in the plants subjected to $2 \mathrm{mM}$ of $\mathrm{B}$ (Figure 3(c)). Although other authors have reported higher $\mathrm{H}_{2} \mathrm{O}_{2}$ and MDA concentrations in the leaves of plants subjected to B toxicity $[6,33]$, our results furthermore indicate that the ROS accumulation was constant and appeared prior to lipid peroxidation. On the other hand, independently of the $\mathrm{B}$ application, the type of cultivar significantly influenced the levels of $\mathrm{H}_{2} \mathrm{O}_{2}$ and MDA (Table 1), with cv. Josefina registering the highest levels of these parameters at days 15 and 10, respectively (Figures 3(b) and 3(c)). 

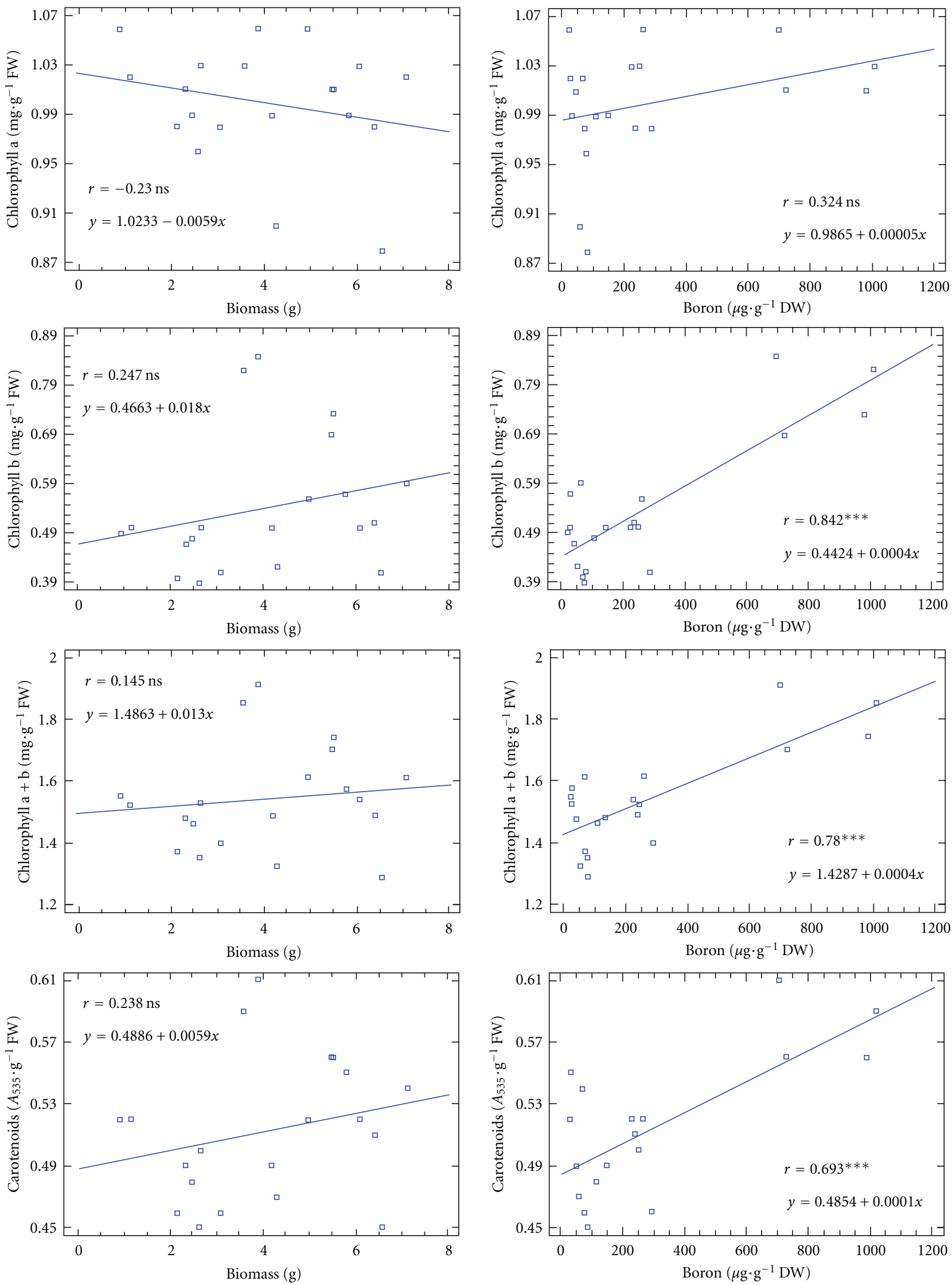

(a)

Figure 9: Continued. 

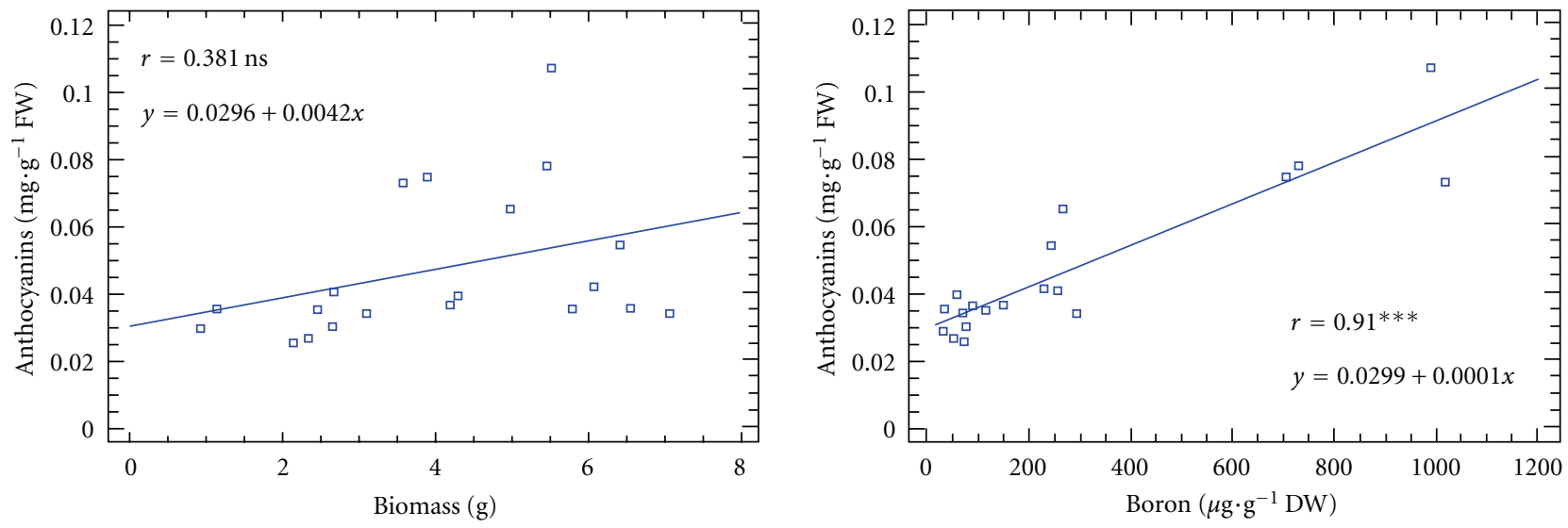

(b)

Figure 9: Analysis of the lineal regression where biomass ( $x$-axis, left) and the foliar concentration in B ( $x$-axis, right) are compared with the concentration of chlorophyll $\mathrm{a}, \mathrm{b}, \mathrm{a}+\mathrm{b}$, carotenoids and anthocyanins ( $y$-axis) in the leaves of two tomato cultivars (Kosaco and Josefina). The significance levels are represented by $*(P<0.05),{ }^{* *}(P<0.01),{ }^{* *}(P<0.001)$, and ns (nonsignificant; $\left.P>0.05\right)$.

Although neither $\mathrm{O}_{2}{ }^{--}$nor $\mathrm{H}_{2} \mathrm{O}_{2}$ correlated with biomass, they registered a positive correlation coefficient that was far higher than that of MDA with respect to the foliar concentration of $\mathrm{B}$ (Figure 4). This was especially high in the case of $\mathrm{O}_{2}{ }^{--}$(Figure 4), possibly because this ROS is more reactive and appears before $\mathrm{H}_{2} \mathrm{O}_{2}$ in the oxidation/reduction chain of oxidative metabolism [32].

One of the most common effects that appear in plants under such abiotic stress as high temperatures, drought, or salinity is the accumulation of osmoprotective solutes such as proline $[11,34,35]$. Among other functions, this amino acid is also attributed with a role in the detoxification of ROS and in the protection of membranes against lipid peroxidation [14]. Under conditions of excessive B, in citrus, apple, and grape, a fall in foliar proline levels has been found and it has been suggested that this is related to the rise in MDA levels independently of the action of other antioxidant mechanisms $[6,10,33]$. On the contrary, in a previous study with barley plants under excess B, Karabal et al. [36] detected no relation between levels of proline and MDA.

In the present experiment, 10 and 15 days after the different $\mathrm{B}$ treatments, both tomato cultivars showed a greater proline concentration under the treatment with $2 \mathrm{mM}$ of $\mathrm{B}$ (Figure 5). In the case of cv. Josefina, on day 15 , an increase in this parameter was noted also under the $0.5 \mathrm{mM}$ treatment (Figure 5), although regardless of the treatments the type of cultivar used in the experiment did not influence the proline levels (Table 1). Similarly, Eraslan et al. [37] reported higher proline levels in the leaves of tomato and pepper under B toxicity. Proline can be accumulated either for an increase in its biosynthesis or for an alteration in protein synthesis/degradation [13]. The rise of the $\mathrm{B}$ concentration to toxic levels in the medium triggered changes in $\mathrm{N}$ metabolism that could suggest the remobilization of amino acids towards the meristem tissues [17]. Therefore, as occurs under other stress conditions [38], the higher proline concentration in mature leaves could be a result of the regulation of the $\mathrm{N}$ metabolism. In any case, an examination of the biomass and $\mathrm{B}$ concentration in relation to the proline levels in the present work indicates a positive correlation between the accumulation of this amino acid and that of $B$ in the leaves (Figure 6), although there is no correlation with biomass (Figure 6). This suggests that, regardless of a protective role, the increase in the proline concentration is another direct consequence of the stress caused by B toxicity in tomato plants.

Another possible indication of the presence of abiotic stress in the plant is the alteration of the composition of pigments in the leaf, particularly chlorophylls, carotenoids, and some phenolic compounds such as anthocyanins. The main pigments are chlorophylls, given that they are directly involved in the uptake and conversion of light energy for photosynthesis [39]. In our study, the application of high B concentrations in the medium prompted certain changes in the concentration of these pigments, primarily cv. Josefina (Figure 7). Although cv. Kosaco did not show significant changes either in the chlorophyll concentration or in the chlorophyll $\mathrm{a}+\mathrm{b}$ concentration, as in $\mathrm{cv}$. Josefina, after 15 days from the beginning of the experiment, a greater accumulation of chlorophyll $\mathrm{b}$ was detected for the $2 \mathrm{mM}$ B treatment (Figure 7(b)). Nevertheless, irrespective of the treatments, the cultivar did not significantly influence the chlorophyll levels (Table 1).

The chlorophyll content is one of the main factors that reflects the photosynthetic rate [40] and biomass production [41]. Although a more detailed study is needed, it is probable that the changes in the chlorophyll concentration in tomato plants subjected to high levels of B, mainly under the 2-mM treatment, is a response to compensate for the loss of leaf area owing to smaller leaf size and larger surface area of necrosis. In the opposite sense, in citrus, it has been observed that B toxicity reduces the chlorophyll concentration $[10,42,43]$, a phenomenon that reflects the strong presence of chlorosis, one of the main symptoms of B toxicity in these plants. On the other hand, similar results were found in the cv. Kosaco by Eraslan et al. [44], who found no significant changes in 

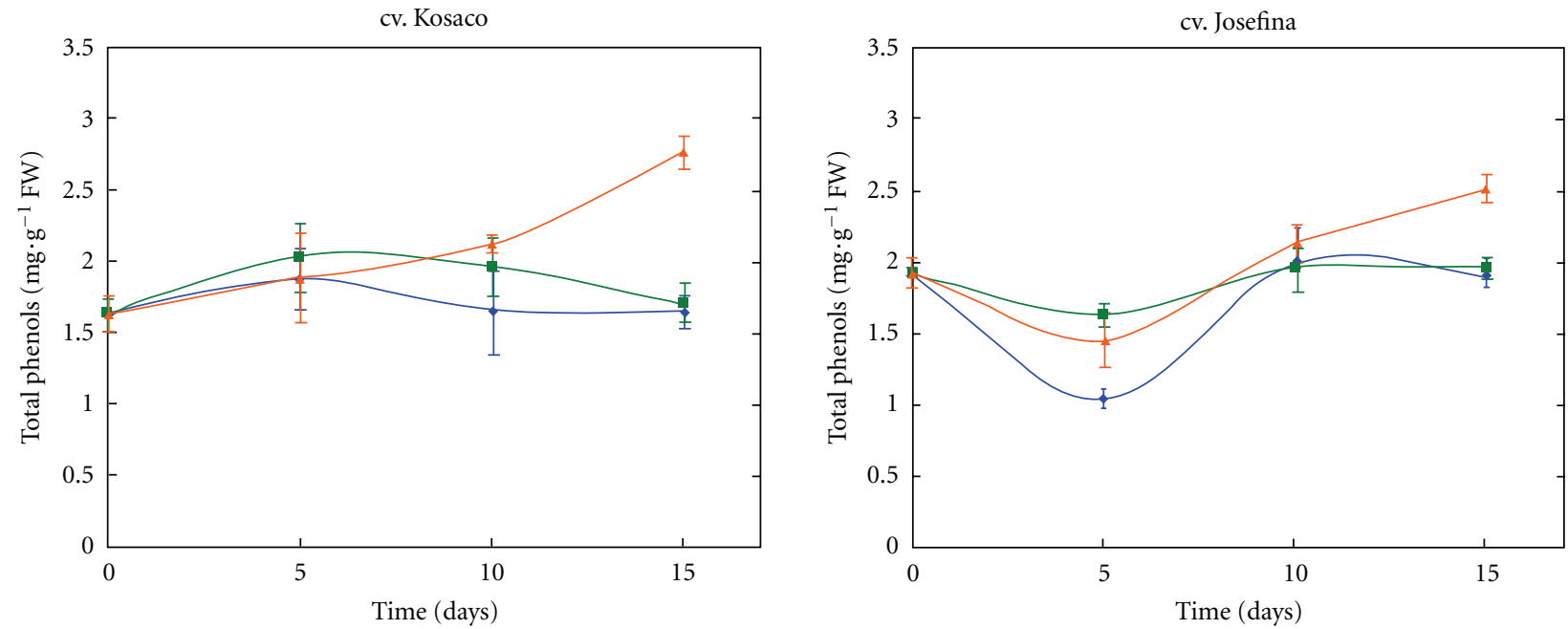

(a)
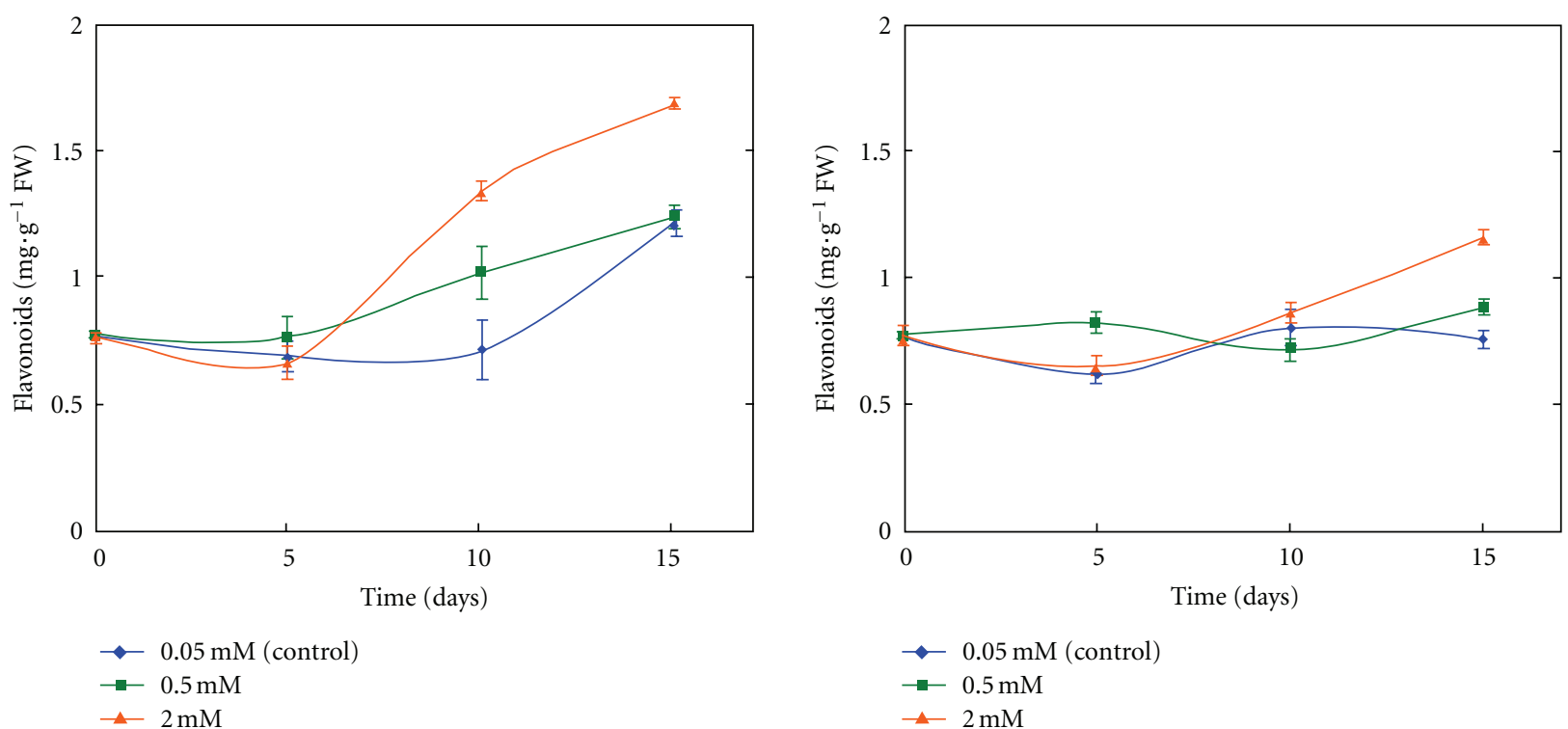

(b)

Figure 10: Changes in the foliar concentration of total phenols (a) and flavonoids (b) over 15 days in two tomato cultivars (Kosaco and Josefina) subjected to $0.05,0.5$, and $2 \mathrm{mM}$ of $\mathrm{B}$. The data represented are means $(n=9) \pm \mathrm{SE}$.

the total chlorophyll concentration of carrot plants (Daucus carota) administered high B levels.

Carotenoids can act as alternative antennas to capture light, absorbing the blue region of the spectrum (400$600 \mathrm{~nm}$ ) and transferring the energy to the chlorophylls. Nevertheless, the main function of carotenoids is to protect the photosynthetic apparatus, dissipating energy to avoid photooxidation [45]. Similarly, the anthocyanins also have an antioxidant role, avoiding the formation of ROS and the oxidative damage of lipids, proteins, and other macromolecules [46]. Therefore, these pigments have been involved in plant tolerance against different types of stress such as drought, UV-B light excess, or heavy-metal toxicity [46].
Under 0.5 and $2 \mathrm{mM}$ of $\mathrm{B}$, the leaves of $\mathrm{cv}$. Josefina showed a greater carotenoid concentration, whereas this did not occur in cv. Kosaco (Figure 8(a)). On the other hand, both cultivars showed a rapid accumulation of anthocyanins after the fifth day from the beginning of the treatments, $\mathrm{cv}$. Kosaco being noteworthy in this case (Figure $8(\mathrm{~b})$ ). Thus, regardless of the $B$ treatment, the cultivar used in the experiment did not influence the levels of either pigment (Table 1). There are few studies that analyse the effects of toxicity on these antioxidants. In a field study using citrus irrigated with water containing high B concentrations, Keles et al. [10] did not find significant changes in the foliar concentration of carotenoids. In carrot leaves, B toxicity did not affect either the carotenoid or anthocyanin concentrations [44]. 

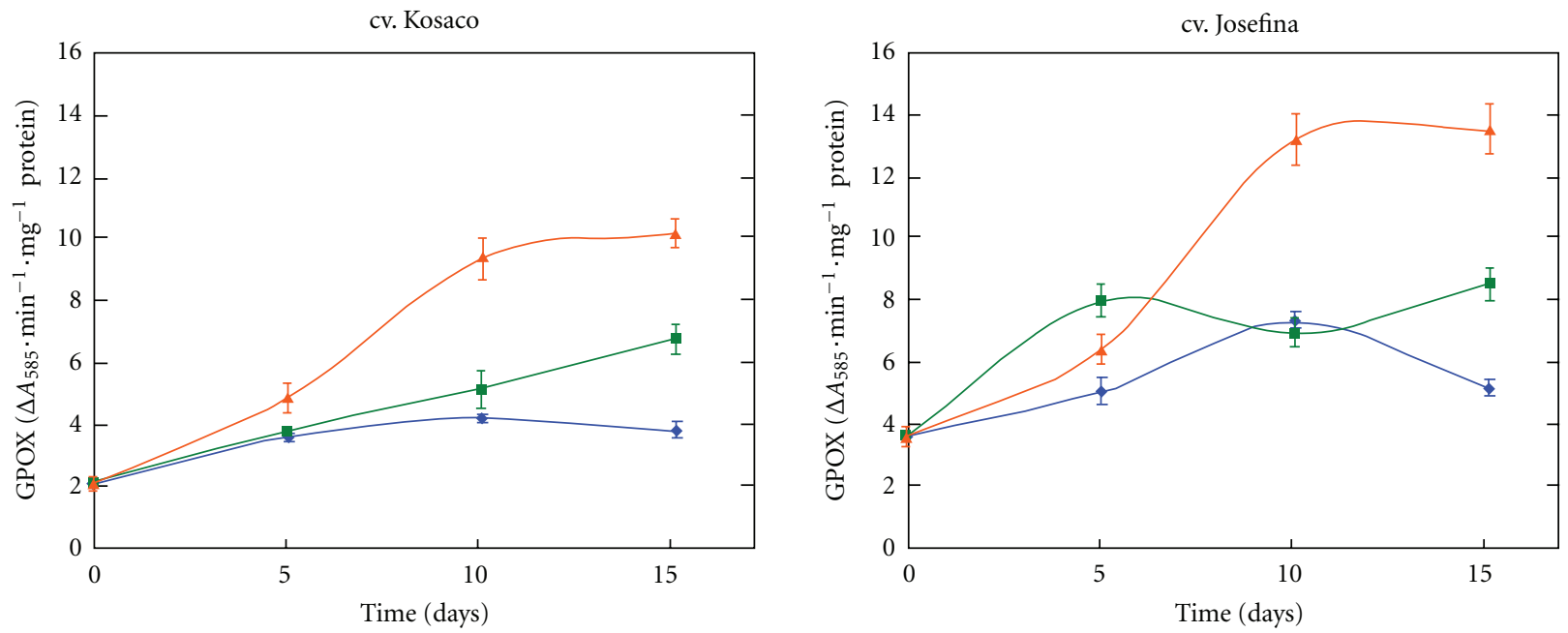

(a)
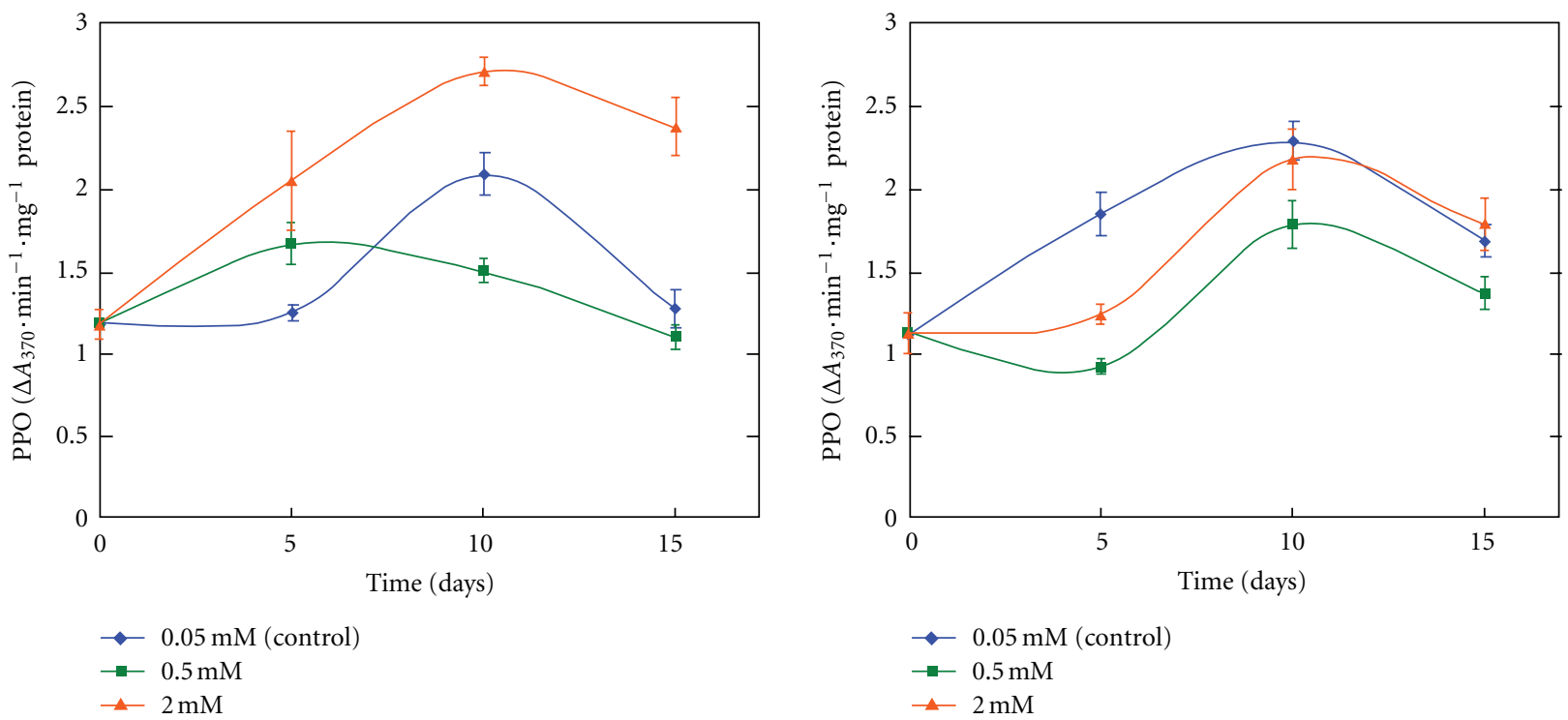

(b)

FIgure 11: Changes in the foliar concentration of PPO (a), and GPOX (b) over 15 days in two tomato cultivars (Kosaco and Josefina) subjected to $0.05,0.5$, and $2 \mathrm{mM}$ of $\mathrm{B}$. The data represented are means $(n=9) \pm \mathrm{SE}$.

Similarly, in spinach (Spinacia oleracea), significant changes were not detected, either, in the foliar concentration of this pigment [47]. Nevertheless, as observed for various kinds of abiotic stress, where the anthocyanins appear to play an important role in defence [46], the present results for tomato suggest that these pigments could be involved in the protection against oxidative stress triggered by $\mathrm{B}$ toxicity.

When biomass and foliar B concentrations were compared with the levels of the different pigments analysed in the tomato leaf, the results indicated that, except for chlorophyll a, all correlated strongly with foliar B levels (Figure 9). Among these, the highest correlation coefficient was found for anthocyanins (Figure 9). This again suggests that this pigment was important in the response of the plants to B toxicity, possibly helping to avoid oxidative damage and therefore to maintain plant development stable.
Phenols are compounds derived from the secondary metabolism and have multiple functions in the plant, including an antioxidant capacity, as occurs in the case of flavonoids, which accumulate in the plant tissues against different types of biotic and abiotic stress [48, 49]. These latter compounds are polyphenol complexes formed by two aromatic rings bonded to a heterocycle and constitute a broad group of compounds that include the anthocyanins [50]. In the present study with tomato plants, the total concentration both of phenols and of flavonoids significantly increased under the treatment with $2 \mathrm{mM}$ of B (Figure 10), with cv. Kosaco registering the higher concentrations of the two cultivars under this treatment (Figure 10). However, in citrus, Keles et al. [10] found no significant changes in the phenol concentration when the irrigation water contained high B levels. 

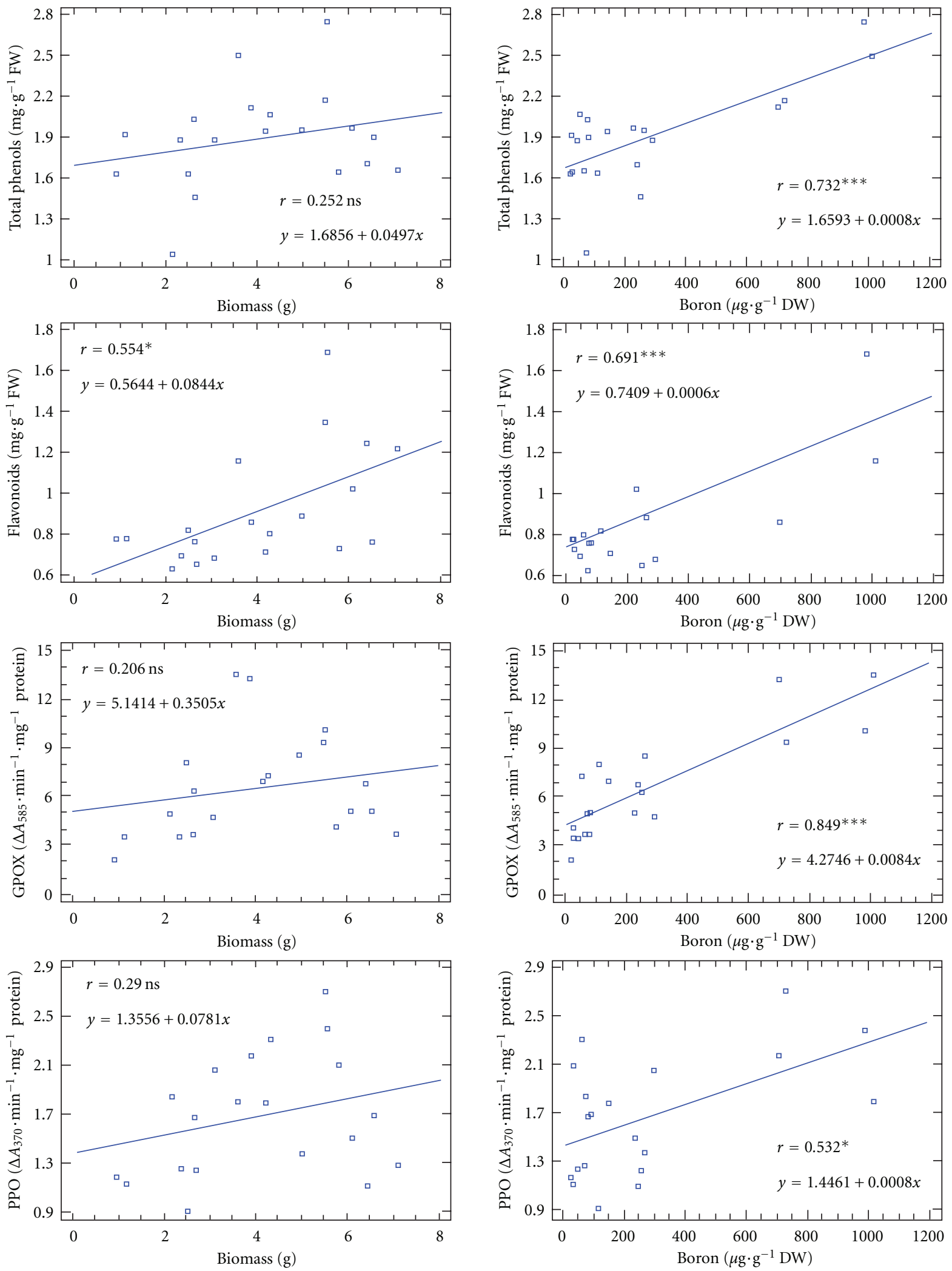

FIGURE 12: Analysis of the lineal regression where biomass ( $x$-axis, left) and the foliar concentration in B ( $x$-axis, right) are compared with the concentration of total phenols, flavonoids and GPOX and PPO activities ( $y$-axis) in the leaves of two tomato cultivars (Kosaco and Josefina). The significance levels are represented by $*(P<0.05), * *(P<0.01)$, *** $(P<0.001)$, and ns (nonsignificant; $P>0.05)$. 
TABle 1: A factorial ANOVA analysing the independent effect of the type of cultivar (CV) and boron treatment (B) used, as well as the sampling day $(\mathrm{T})$ on the parameters analysed in this work.

\begin{tabular}{|c|c|c|c|c|c|c|}
\hline \multirow{3}{*}{$\begin{array}{l}\text { Dependent variable } \\
\text { Biomass }\end{array}$} & \multicolumn{6}{|c|}{ Independent variable } \\
\hline & \multicolumn{2}{|c|}{$\mathrm{CV}$} & \multicolumn{2}{|c|}{ B } & \multicolumn{2}{|c|}{$T$} \\
\hline & 23.07 & $* * * 1$ & 3.02 & ns & 82.70 & $* * *$ \\
\hline Foliar area & 13.99 & $* * *$ & 14.86 & $* * *$ & 27.81 & $* * *$ \\
\hline Total B & 4.47 & $*$ & 287.24 & $* * *$ & 61.87 & $* * *$ \\
\hline $\mathrm{O}_{2}^{\cdot-}$ & 0.08 & ns & 49.63 & $* * *$ & 6.78 & $* * *$ \\
\hline $\mathrm{H}_{2} \mathrm{O}_{2}$ & 9.09 & $* *$ & 56.90 & $* * *$ & 18.17 & $* * *$ \\
\hline MDA & 37.54 & $* * *$ & 24.70 & $* * *$ & 52.38 & $* * *$ \\
\hline Proline & 0.95 & ns & 15.79 & $* * *$ & 14.52 & $* * *$ \\
\hline Chlorophyll a & 1.27 & ns & 3.99 & $*$ & 1.68 & ns \\
\hline Chlorophyll b & 0.02 & ns & 16.49 & $* * *$ & 7.89 & $* * *$ \\
\hline Chlorophyll $\mathrm{a}+\mathrm{b}$ & 0.02 & ns & 12.32 & $* * *$ & 4.77 & $* *$ \\
\hline Carotenoids & 0.48 & ns & 8.43 & $* * *$ & 6.41 & $* * *$ \\
\hline Anthocyanins & 0.08 & ns & 68.71 & $* * *$ & 31.27 & $* * *$ \\
\hline Phenols & 15.56 & $* * *$ & 930.13 & $* * *$ & 24.50 & $* * *$ \\
\hline Flavonoids & 33.88 & $* * *$ & 12.80 & $* * *$ & 51.39 & $* * *$ \\
\hline GPX & 85.29 & $* * *$ & 99.86 & $* * *$ & 30.45 & $* * *$ \\
\hline $\mathrm{PPO}$ & 1.84 & ns & 29.74 & $* * *$ & 25.51 & $* * *$ \\
\hline
\end{tabular}

The significance levels were represented as: $*(P<0.05),{ }^{* *}(P<0.01),{ }^{* * *}(P<0.001)$ and ns (not significant, $\left.P>0.05\right)$.

Some enzymes involved in phenolic metabolism, such as PPO peroxidase, in general respond actively to the presence of stress in the plant [48]. These enzymes can react with flavonoids to produce semiquinones capable of detoxifying different types of ROS, or, as occurs with peroxidases, mediate reactions in which $\mathrm{H}_{2} \mathrm{O}_{2}$ is reduced to $\mathrm{H}_{2} \mathrm{O}$ [50]. After 5 days from the start of the present experiment, both tomato cultivars showed greater GPX activity in leaves under conditions of excess B (Figure 11(a)). Thus, the cv. Kosaco is also characterized by presenting a quick rise in PPO activity under $2 \mathrm{mM}$ of B (Figure 11(b)), although, regardless of the treatment, the cultivar did not significantly influence this parameter (Table 1).

A comparison of the biomass and the foliar concentration of $\mathrm{B}$ with the phenol and flavonoid concentration, as well as with the activity of PPO and GPX, indicated that these parameters correlated significantly with the foliar B levels, while the flavonoid concentration was the only one that presented a certain correlation with biomass (Figure 12). These findings, together with the result found for the levels of ROS and anthocyanins, indicate the importance of the oxidative metabolism and the antioxidant response in tomato plants submitted to B toxicity, given that they reflect the influence of the successive accumulation of this micronutrient in the leaf.

In the present experimental block, it was found that the tomato plants were capable of maintaining their growth for at least 10 days despite the rapidly accumulating $\mathrm{B}$ concentrations to levels far higher than optimal. In this case, the $\mathrm{cv}$. Kosaco plants submitted to $0.5 \mathrm{mM}$ of B (Figures 1(a) and 2) displayed outstanding performance. One of the primary factors that affect plant growth is the ability to capture light energy [41]. In this sense, the reduction of the leaf area could be a major cause of stifled growth in plants exposed to B toxicity (Figure 1(b)), this situation related perhaps not only to the smaller leaf size but also to the greater amount of leaf necrosis. Here, too, it bears highlighting that the $\mathrm{cv}$. Kosaco plants submitted to $0.5 \mathrm{mM}$ of B presented a foliar area very similar to that of the control treatment throughout the experiment (Figure 1(b)), suggesting again that this cultivar is less sensitive to excessive B than is the $\mathrm{cv}$. Josefina.

Each type of abiotic stress requires a different acclimation response that varies depending on the specific needs of each plant [51]. In this block, it was confirmed that, in general, the indicators of abiotic stress analysed were independent of biomass under the experimental conditions. However, most of these indicators appear to have a close relationship with foliar B levels, with a notably high correlation coefficient of $\mathrm{O}_{2}{ }^{\bullet-}$ (Figure 4(a)) and anthocyanins (Figure 9). The excess B in the medium triggered oxidative stress, to which the plant responded with an increase in antioxidant activity [8].

In this sense, it was found that the first indication of the presence of high $\mathrm{B}$ concentrations in the leaf was the rise in the levels of $\mathrm{O}_{2}{ }^{--}$and $\mathrm{H}_{2} \mathrm{O}_{2}$ (Figures 3(a) and 3(b)), a phenomenon followed closely by the rise in the levels of proline (Figure 5) and anthocyanins (Figure 8(b)). This implies that the ROS levels in the leaf constitute a reliable parameter to evaluate the degree of stress provoked by this nutritional imbalance in tomato plants. In addition, the results shown in the present work confirm the importance of the antioxidant response under this nutritional stress. 
Many phenolic compounds are precursors of antioxidant molecules required by peroxidases, being indicators of the stress level of the plant under different adverse conditions $[48,49]$. In the present work, it was confirmed that among other parameters, GPX activity is one of the best indicators of the activation of phenolic metabolism under B toxicity (Figure 12). After 15 days from the beginning of the experiment, the cv. Kosaco presented a higher concentration of phenols and flavonoids (Figure 10), and moreover, as opposed to cV. Josefina, showed a rapid increase in PPO activity (Figure 11). Therefore, as noted by our group in the lignification studies under B toxicity [16], some aspects of phenolic metabolism may also be involved in the different degree of sensitivity to excessive B shown by both tomato cultivars.

\section{Acknowledgments}

This work is dedicated to the memory of Dr. Luis Miguel Cervilla. This work was supported by Plan Nacional de $\mathrm{I}+\mathrm{D}+\mathrm{i}$ of Ministerio de Educación y Ciencia, Spain (AGL2006-03164/AGR).

\section{References}

[1] R. O. Nable, G. S. Bañuelos, and J. G. Paull, "Boron toxicity," Plant and Soil, vol. 193, no. 1-2, pp. 181-198, 1997.

[2] FAOSTAT, October 2007 http://faostat.fao.org/site/567/DesktopDefault.aspx?PageID=567).

[3] J. L. Parks and M. Edwards, "Boron in the environment," Critical Reviews in Environmental Science and Technology, vol. 35, no. 2, pp. 81-114, 2005.

[4] M. Juan, R. M. Rivero, L. Romero, and J. M. Ruiz, "Evaluation of some nutritional and biochemical indicators in selecting salt-resistant tomato cultivars," Environmental and Experimental Botany, vol. 54, no. 3, pp. 193-201, 2005.

[5] E. Sánchez-Rodríguez, M. Rubio-Wilhelmi, L. M. Cervilla et al., "Genotypic differences in some physiological parameters symptomatic for oxidative stress under moderate drought in tomato plants," Plant Science, vol. 178, no. 1, pp. 30-40, 2010.

[6] A. Molassiotis, T. Sotiropoulos, G. Tanou, G. Diamantidis, and I. Therios, "Boron-induced oxidative damage and antioxidant and nucleolytic responses in shoot tips culture of the apple rootstock EM 9 (Malus domestica Borkh)," Environmental and Experimental Botany, vol. 56, no. 1, pp. 54-62, 2006.

[7] T. E. Sotiropoulos, A. Molassiotis, D. Almaliotis et al., "Growth, nutritional status, chlorophyll content, and antioxidant responses of the apple rootstock MM 111 shoots cultured under high boron concentrations in vitro," Journal of Plant Nutrition, vol. 29, no. 3, pp. 575-583, 2006.

[8] L. M. Cervilla, B. Blasco, J. J. Ríos, L. Romero, and J. M. Ruiz, "Oxidative stress and antioxidants in tomato (Solanum lycopersicum) plants subjected to boron toxicity," Annals of Botany, vol. 100, no. 4, pp. 747-756, 2007.

[9] J. M. Ruiz, R. M. Rivero, and L. Romero, "Preliminary studies on the involvement of biosynthesis of cysteine and glutathione concentration in the resistance to B toxicity in sunflower plants," Plant Science, vol. 165, no. 4, pp. 811-817, 2003.

[10] Y. Keles, I. Öncel, and N. Yenice, "Relationship between boron content and antioxidant compounds in Citrus leaves taken from fields with different water source," Plant and Soil, vol. 265, no. 1-2, pp. 345-353, 2004.

[11] A. Parvaiz and S. Satyawati, "Salt stress and phyto-biochemical responses of plants-a review," Plant, Soil and Environment, vol. 54, no. 3, pp. 89-99, 2008.

[12] P. D. Hare, W. A. Cress, and J. Van Staden, "Proline synthesis and degradation: a model system for elucidating stress-related signal transduction," Journal of Experimental Botany, vol. 50, no. 333, pp. 413-434, 1999.

[13] W. Claussen, "Proline as a measure of stress in tomato plants," Plant Science, vol. 168, no. 1, pp. 241-248, 2005.

[14] Z. Hong, K. Lakkineni, Z. Zhang, and D. P. S. Verma, "Removal of feedback inhibition of $\Delta 1$-pyrroline-5-carboxylate synthetase results in increased proline accumulation and protection of plants from osmotic stress," Plant Physiology, vol. 122, no. 4, pp. 1129-1136, 2000.

[15] J. B. Harborne and C. A. Williams, "Advances in flavonoid research since 1992," Phytochemistry, vol. 55, no. 6, pp. 481$504,2000$.

[16] L. M. Cervilla, M. A. Rosales, M. M. Rubio-Wilhelmi et al., "Involvement of lignification and membrane permeability in the tomato root response to boron toxicity," Plant Science, vol. 176, no. 4, pp. 545-552, 2009.

[17] L. M. Cervilla, B. Blasco, J. J. Ríos et al., "Response of nitrogen metabolism to boron toxicity in tomato plants," Plant Biology, vol. 11, no. 5, pp. 671-677, 2009.

[18] B. Wolf, "Improvement in the azomethine-H method for determination of boron," Communications of Soil Science and Plant Analysis, vol. 5, no. 1, pp. 39-44, 1974.

[19] N. Doke, "Involvement of superoxide anion generation in the hypersensitive response of potato tuber tissues to infection with an incompatible race of Phytophthora infestans and to the hyphal wall components," Physiological Plant Pathology, vol. 23, no. 3, pp. 345-357, 1983.

[20] J. Kubiś, "Exogenous spermidine differentially alters activities of some scavenging system enzymes, $\mathrm{H}_{2} \mathrm{O}_{2}$ and superoxide radical levels in water-stressed cucumber leaves," Journal of Plant Physiology, vol. 165, no. 4, pp. 397-406, 2008.

[21] S. P. Mukherjee and M. A. Choudhuri, "Implications of water stress-induced changes in the levels of endogenous ascorbic acid and hydrogen peroxide in Vigna seedlings," Physiologia Plantarum, vol. 58, no. 2, pp. 166-170, 1983.

[22] J. Fu and B. Huang, "Involvement of antioxidants and lipid peroxidation in the adaptation of two cool-season grasses to localized drought stress," Environmental and Experimental Botany, vol. 45, no. 2, pp. 105-114, 2001.

[23] J. J. Irigoyen, D. W. Emerich, and M. Sánchez-Díaz, "Water stress induced changes in concentrations of proline and total soluble sugars in nodulated alfalfa (Medicago sativa) plants," Physiologia Plantarum, vol. 84, no. 1, pp. 55-60, 1992.

[24] A. R. Wellburn, "The spectral determination of chlorophylls a and b, as well as total carotenoids, using various solvents with spectrophotometers of different resolution," Journal of Plant Physiology, vol. 144, no. 3, pp. 307-313, 1994.

[25] C. A. Ticconi, C. A. Delatorre, and S. Abel, "Attenuation of phosphate starvation responses by phosphite in Arabidopsis," Plant Physiology, vol. 127, no. 3, pp. 963-972, 2001.

[26] R. M. Rivero, J. M. Ruiz, P. C. García, L. R. López-Lefebre, E. Sánchez, and L. Romero, "Resistance to cold and heat stress: accumulation of phenolic compounds in tomato and watermelon plants," Plant Science, vol. 160, no. 2, pp. 315-321, 2001. 
[27] D. O. Kim, S. W. Jeong, and C. Y. Lee, "Antioxidant capacity of phenolic phytochemicals from various cultivars of plums," Food Chemistry, vol. 81, no. 3, pp. 321-326, 2003.

[28] E. N. Aquino-Bolaños and E. Mercado-Silva, "Effects of polyphenol oxidase and peroxidase activity, phenolics and lignin content on the browning of cut jicama," Postharvest Biology and Technology, vol. 33, no. 3, pp. 275-283, 2004.

[29] A. Kalir, G. Omri, and A. Poljakoff-Mayber, "Peroxidase and catalase activity in leaves of Halimione portulacoides exposed to salinity," Physiologia Plantarum, vol. 62, no. 2, pp. 238-244, 1984.

[30] N. Verbruggen, C. Hermans, and H. Schat, "Molecular mechanisms of metal hyperaccumulation in plants," New Phytologist, vol. 181, no. 4, pp. 759-776, 2009.

[31] A. R. Stiles, D. Bautista, E. Atalay, M. Babaoğlu, and N. Terry, "Mechanisms of boron tolerance and accumulation in plants: a physiological comparison of the extremely borontolerant plant species, puccinellia distans, with the moderately boron-tolerant gypsophila arrostil," Environmental Science and Technology, vol. 44, no. 18, pp. 7089-7095, 2010.

[32] R. Mittler, "Oxidative stress, antioxidants and stress tolerance," Trends in Plant Science, vol. 7, no. 9, pp. 405-410, 2002.

[33] A. Gunes, G. Soylemezoglu, A. Inal, E. G. Bagci, S. Coban, and O. Sahin, "Antioxidant and stomatal responses of grapevine (Vitis vinifera L.) to boron toxicity," Scientia Horticulturae, vol. 110, no. 3, pp. 279-284, 2006.

[34] J. M. Ruiz, E. Sanchez, P. C. Garcia, L. R. Lopez-Lefebre, R. M. Rivero, and L. Romero, "Proline metabolism and NAD kinase activity in greenbean plants subjected to cold-shock," Phytochemistry, vol. 59, no. 5, pp. 473-478, 2002.

[35] R. M. Rivero, J. M. Ruiz, and L. M. Romero, "Importance of $\mathrm{N}$ source on heat stress tolerance due to the accumulation of proline and quaternary ammonium compounds in tomato plants," Plant Biology, vol. 6, no. 6, pp. 702-707, 2004.

[36] E. Karabal, M. Yücel, and H. A. Öktem, "Antioxidant responses of tolerant and sensitive barley cultivars to boron toxicity," Plant Science, vol. 164, no. 6, pp. 925-933, 2003.

[37] F. Eraslan, A. Inal, A. Gunes, and M. Alpaslan, "Boron toxicity alters nitrate reductase activity, proline accumulation, membrane permeability, and mineral constituents of tomato and pepper plants," Journal of Plant Nutrition, vol. 30, no. 6, pp. 981-994, 2007.

[38] I. Uluisik, A. Kaya, D. E. Fomenko et al., "Boron stress activates the general amino acid control mechanism and inhibits protein synthesis," PLoS One, vol. 6, no. 11, Article ID e27772, 2011.

[39] J. N. Nishio, "Why are higher plants green? Evolution of the higher plant photosynthetic pigment complement," Plant, Cell and Environment, vol. 23, no. 6, pp. 539-548, 2000.

[40] L. Z. Mao, H. F. Lu, Q. Wang, and M. M. Cai, "Comparative photosynthesis characteristics of Calycanthus chinensis and Chimonanthus praecox," Photosynthetica, vol. 45, no. 4, pp. 601-605, 2007.

[41] P. K. Ghosh, Ajay, K. K. Bandyopadhyay et al., "Comparative effectiveness of cattle manure, poultry manure, phosphocompost and fertilizer-NPK on three cropping systems in vertisols of semi-arid tropics. II. Dry matter yield, nodulation, chlorophyll content and enzyme activity," Bioresource Technology, vol. 95, no. 1, pp. 85-93, 2004.

[42] I. E. Papadakis, K. N. Dimassi, A. M. Bosabalidis, I. N. Therios, A. Patakas, and A. Giannakoula, "Boron toxicity in 'Clementine' mandarin plants grafted on two rootstocks," Plant Science, vol. 166, no. 2, pp. 539-547, 2004.

[43] S. Han, N. Tang, H. X. Jiang, L. T. Yang, Y. Li, and L. $\mathrm{S}$. Chen, " $\mathrm{CO}_{2}$ assimilation, photosystem II photochemistry, carbohydrate metabolism and antioxidant system of citrus leaves in response to boron stress," Plant Science, vol. 176, no. 1, pp. 143-153, 2009.

[44] F. Eraslan, A. Inal, A. Gunes, and M. Alpaslan, "Impact of exogenous salicylic acid on the growth, antioxidant activity and physiology of carrot plants subjected to combined salinity and boron toxicity," Scientia Horticulturae, vol. 113, no. 2, pp. 120-128, 2007.

[45] G. E. Bartley and P. A. Scolnik, "Plant carotenoids: pigments for photoprotection, visual attraction, and human health," Plant Cell, vol. 7, no. 7, pp. 1027-1038, 1995.

[46] K. S. Gould, "Nature's Swiss army knife: the diverse protective roles of anthocyanins in leaves," Journal of Biomedicine and Biotechnology, vol. 2004, no. 5, pp. 314-320, 2004.

[47] F. Eraslan, A. Inal, D. J. Pilbeam, and A. Gunes, "Interactive effects of salicylic acid and silicon on oxidative damage and antioxidant activity in spinach (Spinacia oleracea L. cv. Matador) grown under boron toxicity and salinity," Plant Growth Regulation, vol. 55, no. 3, pp. 207-219, 2008.

[48] H. Yamasaki, Y. Sakihama, and N. Ikehara, "Flavonoidperoxidase reaction as a detoxification mechanism of plant cells against $\mathrm{H}_{2} \mathrm{O}_{2}$," Plant Physiology, vol. 115, no. 4, pp. 14051412, 1997.

[49] M. P. Kähkönen, A. I. Hopia, H. J. Vuorela et al., "Antioxidant activity of plant extracts containing phenolic compounds," Journal of Agricultural and Food Chemistry, vol. 47, no. 10, pp. 3954-3962, 1999.

[50] L. Pourcel, J. M. Routaboul, V. Cheynier, L. Lepiniec, and I. Debeaujon, "Flavonoid oxidation in plants: from biochemical properties to physiological functions," Trends in Plant Science, vol. 12, no. 1, pp. 29-36, 2007.

[51] R. Mittler, "Abiotic stress, the field environment and stress combination," Trends in Plant Science, vol. 11, no. 1, pp. 1519, 2006. 

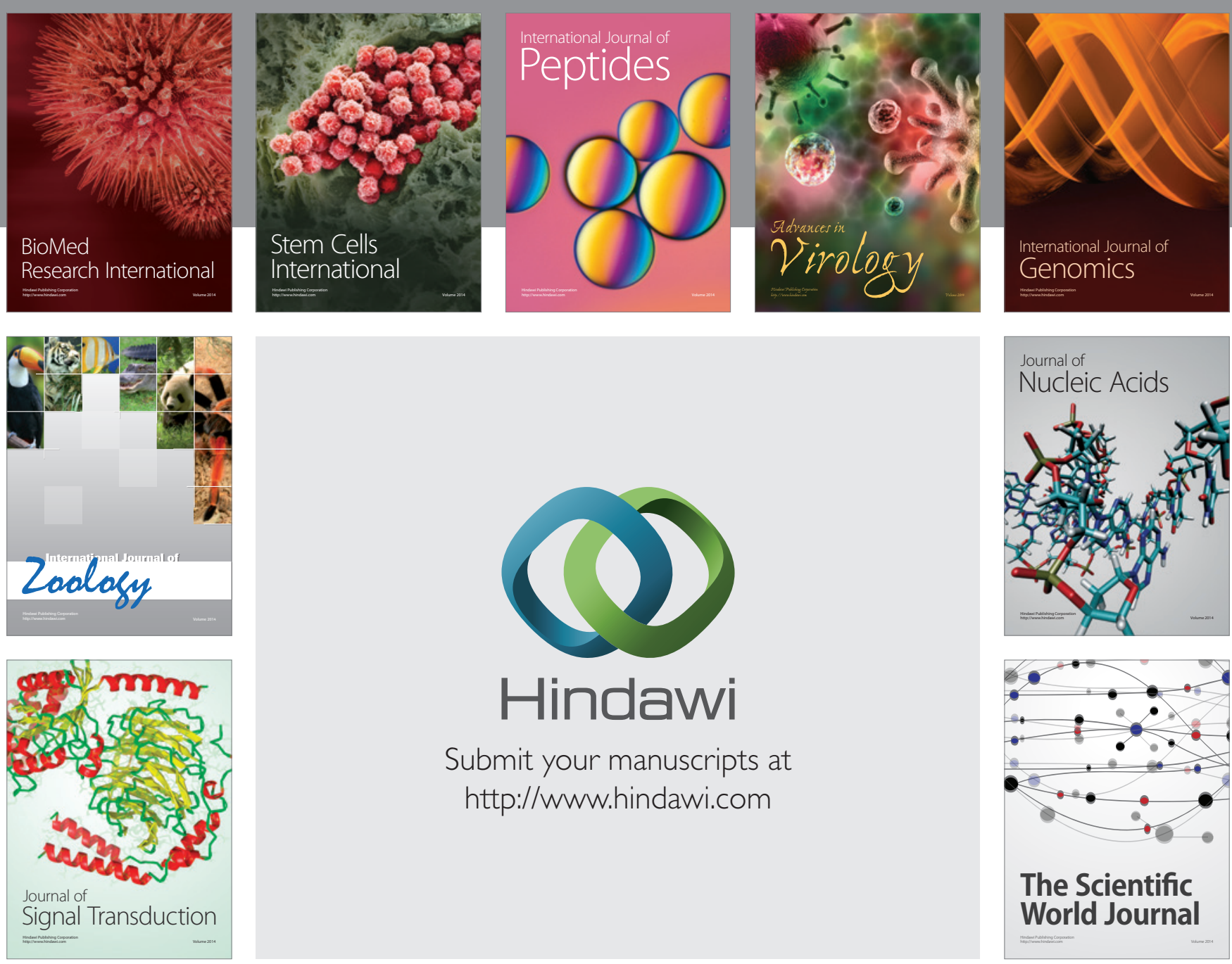

Submit your manuscripts at

http://www.hindawi.com
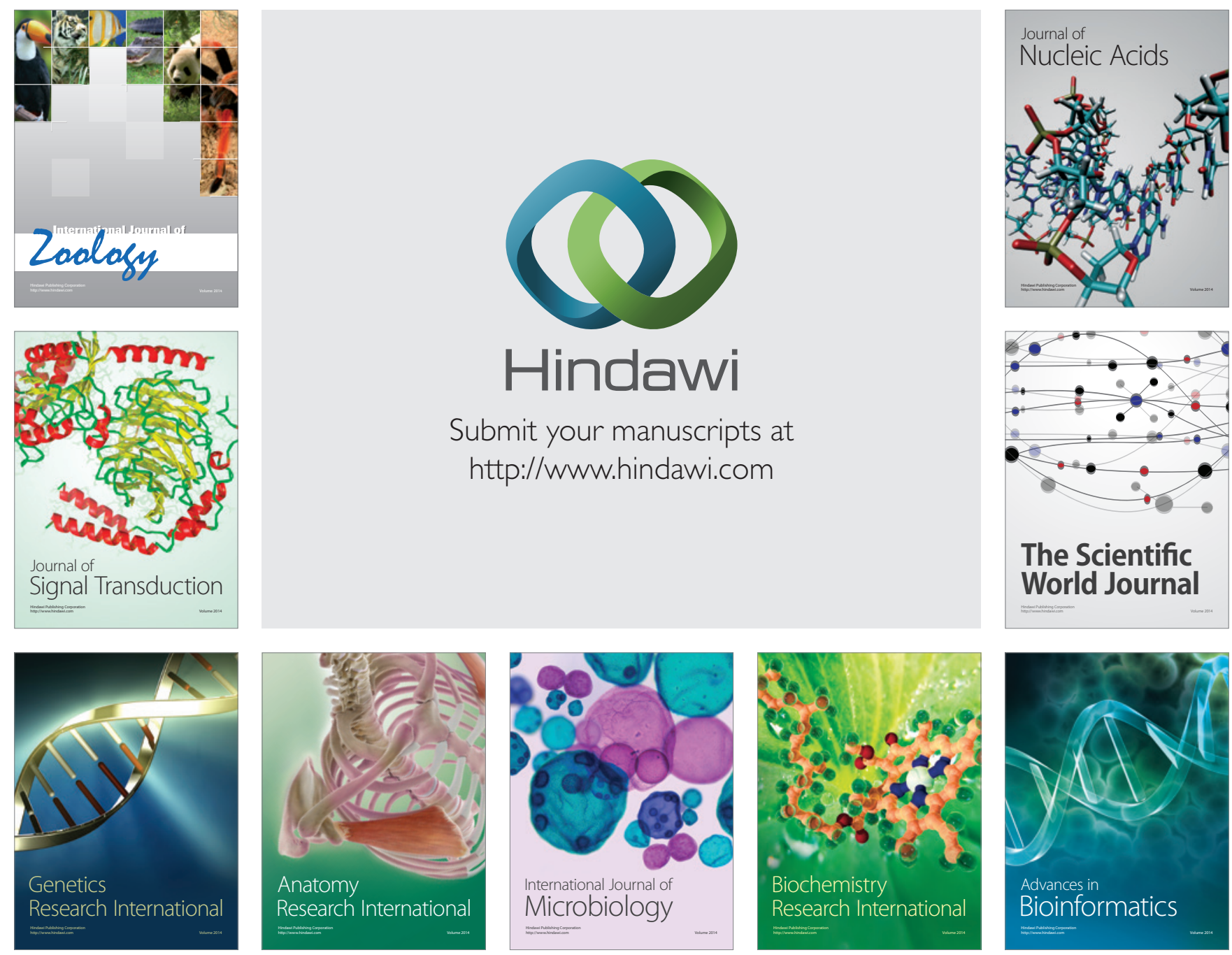

The Scientific World Journal
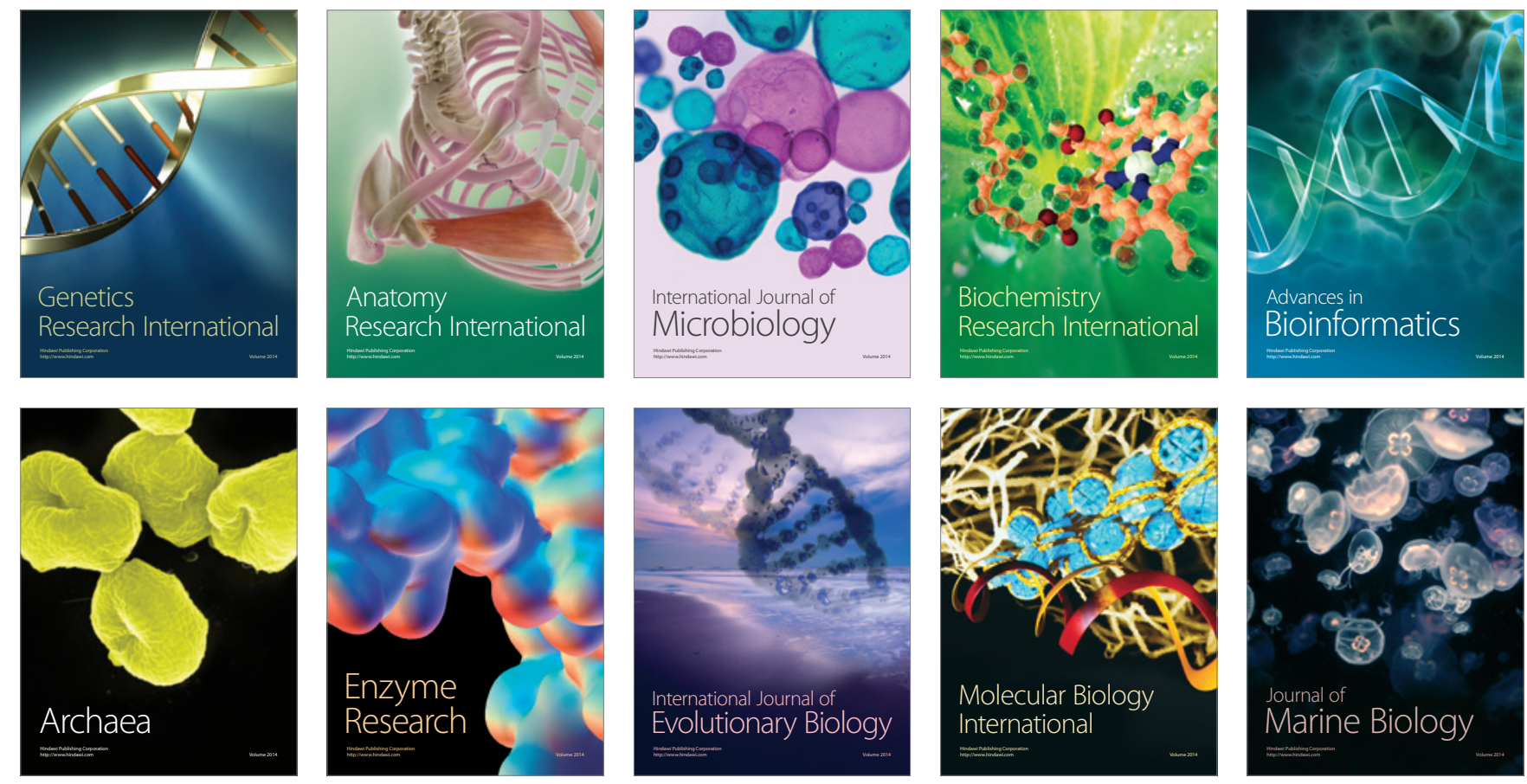